\title{
Field Potential Mapping of Neurons in the Lumbar Spinal Cord Activated following Stimulation of the Mesencephalic Locomotor Region
}

\author{
B. R. Noga, P. A. Fortier, ${ }^{a}$ D. J. Kriellaars, ${ }^{b}$ X. Dai, G. R. Detillieux, and L. M. Jordan \\ Department of Physiology, Faculty of Medicine, University of Manitoba, Winnipeg, Canada, R3E OW3
}

The spinal neurons involved in the control of locomotion in mammals have not been identified, and a major step that is necessary for this purpose is to determine where these cells are likely to be located. The principal objective of this study was to localize lumbar spinal interneurons activated by stimulation of the mesencephalic locomotor region (MLR) of the cat. For this purpose, extracellular recordings of MLR-evoked cord dorsum and intraspinal field potentials were obtained from the lumbosacral enlargement during fictive locomotion in the precollicular-postmammillary decerebrate cat preparation. Potentials recorded from the dorsal surface of the cord between the third lumbar (L3) and first sacral (S1) segments typically showed four shortlatency positive waves (P1-P4). These P-waves were largest between the L4-L6 segments. The amplitude of the P24 waves increased with the appearance of locomotion and displayed rhythmic modulation during the locomotor step cycle. Microelectrode recordings from the L4-L7 spinal segments during fictive locomotion revealed the presence of both positive and negative short-latency MLR-evoked intraspinal field potentials, and were used to construct isopotential maps of the evoked potentials. Positive field potentials were observed throughout the dorsal horn of the L4-L7 spinal segments with the largest amplitude potentials occurring in laminae III-VI. Negative field potentials were found in laminae VI-X of the lumbar cord. The shortest latency negative field potentials were observed in lamina VII and at the border between laminae VI and VII and were considered to be evoked monosynaptically from the arrival of the descending volley. Short-latency monoand disynaptic negative field potentials were also observed in lamina VIII. Longer latency, tri- and polysynaptic field potentials were observed in laminae VII and VIII. Many of the longer latency negative waves observed in laminae VII and VIII followed shorter latency negative potentials recorded from the same location. Laminae VII and VIII negative field potentials were largest in the L5-6 and L4-5 spi-

\footnotetext{
Received Dec. 16. 1993; revised Sept. 21, 1994; accepted Sept. 26, 1994.

We thank K. Madec for technical assistance during the experiments and R. Brownstone and S. Shefchyk for reviewing the manuscript. This research was supported by the Medical Research Council of Canada, the Human Frontiers Science Program, and the Health Sciences Centre Foundation of Winnipeg.

Correspondence should be addressed to Dr. L. M. Jordan at the above address.

aPresent address: Department of Anatomy, 451 Smyth Road, University of Ottawa, Ottawa, Ontario, Canada, K1H 8 M5.

Present address: School of Medical Rehabilitation, University of Manitoba, Winnipeg, Manitoba, Canada, R3E 0W3.

Copyright (C) 1995 Society for Neuroscience 0270-6474/95/152203-15\$05.00/0
}

nal segments, respectively. Negative field potentials were also evoked in the motor nuclei of the L4-7 spinal segments. The segmental latencies for these potentials indicate that they were evoked di- and trisynaptically. Di- and trisynaptic negative field potentials were also observed near the central canal (in lamina $X$ and the adjacent medial lamina VII) of the L5 and L6 segments. The MLR-evoked negative field potentials were modulated during fictive locomotion. These results suggest that stimulation of the MLR produces a descending volley that activates interneurons in the intermediate zone and ventral horn throughout the lumbosacral segments of the spinal cord, but predominantly between L4 and L6. We propose that the neurons giving rise to MLR-evoked cord dorsum and negative field potentials form part of the spinal circuitry responsible for the initiation and/or maintenance of locomotion.

[Key words: field potentials, interneurons, spinal cord, fictive locomotion, mesencephalic locomotor region]

The pioneering studies of Shik and co-workers $(1966,1967)$ provided a preparation that has been useful in the study of the central pathways and neuronal mechanisms involved in the initiation and control of locomotion. They demonstrated that stimulation of the mesencephalic locomotor region (MLR) in the precollicular-postmammillary decerebrate cat resulted in the initiation of a locomotor rhythm that persisted throughout the period of electrical stimulation. Subsequent investigations using this preparation combined with the local application of putative transmitters have shown that the locomotor effects observed with stimulation of the MLR may result from the activation of cells and not fibers passing through this region (Garcia-Rill et al., 1985). Neurons within the MLR receive descending afferents from a number of areas including the motor cortex and basal ganglia (Shik et al., 1968; Garcia-Rill et al., 1981; see Armstrong, 1986; Garcia-Rill, 1986, for review) and may, thus, serve as an integration center from higher brain centers for the initiation of locomotion.

The MLR projects mainly to the medial reticular formation, in the vicinity of gigantocellular and magnocellular reticulospinal cells (Garcia-Rill et al., 1983; Steeves and Jordan, 1984) and does not project directly to the spinal cord. Although the MLR has been shown to project to other areas (Garcia-Rill et al., 1983), recent experiments have established that the pathway to the medial reticular formation is the essential component of the descending pathway to the spinal cord responsible for the initiation of locomotion (Noga et al., 1988, 1991a). Reticulospinal cells within the medial reticular formation that are involved in 
the initiation of locomotion project to the spinal cord via the ventrolateral funiculus (Steeves and Jordan, 1980; Jordan, 1986, 1991; Noga et al., 1991a). Stimulation of the MLR produces postsynaptic potentials in lumbar motoneurons, and the latencies of the excitatory postsynaptic potentials produced in this manner suggest a di- or trisynaptic segmental linkage (Shefchyk and Jordan, 1985; Noga, 1988). Although recordings from rhythmically active spinal neurons during evoked locomotion have been described in several studies (Arshavskii et al., 1972; Orlovsky and Feldman, 1972; Feldman and Orlovsky, 1975; Edgerton et al., 1976; Baev et al., 1979; McCrea et al., 1980; Arshavsky et al., 1986; Noga et al., 1987a; Pratt and Jordan, 1987; Hishinuma and Yamaguchi, 1990; Tcrakado and Yamaguchi, 1990; Ichikawa et al., 1991; Viala et al., 1991; Yamaguchi, 1991, 1992), only a few types of spinal neurons have been examined in relation to synaptic activation by stimuli applied to the MLR or coextensive structures such as the cuneiform nucleus (Kazennikov et al., 1983; Edgley et al., 1988; Jankowska and Noga, 1990; Shefchyk et al., 1990; Jordan and Noga, 1991).

The spinal cells that are necessary for initiation of locomotion elicited by MLR stimulation have not been identified. The objective of the present study was to document the locations of lumbar interneurons that are activated by stimulation of the MLR. These cells could be activated because they are interposed in the pathway from the MLR to motoneurons (Shefchyk and Jordan, 1985; Noga, 1988) or because they form part of or receive inputs from the locomotor rhythm generator. For this purpose, an analysis of evoked potentials in the spinal cord, which are produced by electrical stimulation of the MLR, was carried out.

The presence of cord dorsum potentials and extracellular focal negative field potentials recorded intraspinally can be used to locate interneurons activated by a discrete pathway (e.g., Skinner and Willis, 1970; Fu et al., 1974; Skinner and Remmel, 1978; Edgley and Jankowska, 1987a). Isopotential mapping techniques (see Willis, 1980, for review) were used in this study to aid in localizing focal negative field potentials evoked by stimuli applied to the MIR. The results show that MI,R stimulation produces field potentials at latencies consistent with the activation of interneurons in the short-latency pathway to the hindlimb motoneurons. These field potentials were present throughout the lumbar segments examined (L4-7). The largest negative field potentials were found in the L4-L6 segments and appeared to originate from cells in Rexed's laminae VI-X.

Preliminary reports of some of this data have been published (Fortier et al., 1988; Jordan, 1991).

\section{Materials and Methods}

\section{Animal preparation}

Experiments were carried out on 16 adult cats weighing between 1.9 are $4.0 \mathrm{~kg}$. Each cat was initially anesthetized with halothane in a mixture of $70 \%$ nitrous oxide and $30 \%$ oxygen delivered through a face mask. The trachea was then intubated for direct administration of the anesthetic. The left common carotid was cannulated and connected to a pressure transducer for blood pressure monitoring. The right external jugular and the left brachial veins were cannulated for the administration of fluids. Each animal was given $2-4 \mathrm{mg}$ of dexamethasone (Hexadrol, phosphate, Organon) to reduce tissue swelling. A bicarbonate solution (100 mM NaHCO 3 with $5 \%$ glucose) was infused at $5 \mathrm{ml} / \mathrm{hr}$ throughout the experiment to help maintain a normal $\mathrm{pH}$ balance. The laminae from L4-7 segments were removed to expose the underlying spinal cord. A number of hindlimb nerves were dissected free bilaterally. These included nerves to anterior and medial biceps $(\mathrm{AB})$, posterior biceps (PB), semimembranosus (SM), semitendinosus (ST), medial gastrocnemius (MG), lateral gastrocnemius-soleus (LG), and tibialis anterior (TA) mus- cles. Branches of the femoral nerve ipsilateral to the side of recording (left) were also cut and mounted in a cuff electrode. These included vastus lateralis, intermedialis, and medialis (Vast), and sartorius anterior and medialis (SA). The contralateral femoral nerve was cut in order to provide similar denervation bilaterally.

The cat was placed in a Transvertex headframe and suspended with all four limbs pendant. The sciatic nerves were placed in custom-made horizontal nerve trays filled with mineral oil and mounted on bipolar electrodes. The spinal cord was covered with mineral oil maintained at $37^{\circ} \mathrm{C}$ using a feedback-controlled heating lamp. Following a craniotomy, the anesthesia was discontinued and a precollicular-postmammillary decerebration was performed on each animal. The animals were paralyzed with gallamine triethiodide (Flaxedil, Rhone-Poulenc; $-4 \mathrm{mg} / \mathrm{kg}$ / $\mathrm{hr}$ ) and artificially ventilated. The end tidal $\mathrm{CO}_{2}$ was maintained between 3.5 and $4.5 \%$. Blood lost during the decerebration $(1-3 \mathrm{ml})$ was replaced with a perfluorocarbon blood substitute, Oxypherol-E.T. (Alpha Therapeutic Corp., Los Angeles, CA). Dextran (Travenol) was also administered intravenously as necessary to maintain blood pressure at or above $80 \mathrm{~mm} \mathrm{Hg}$. Body temperature was maintained at approximately $37^{\circ} \mathrm{C}$.

\section{Stimulation, data collection, and analysis}

Following a recovery period of $1-1.5 \mathrm{hr}$ after the decerebration, locomotion was evoked by electrical stimulation of the MLR $(0.5-1.0 \mathrm{msec}$ square wave pulses, 14-25 Hz, 100-220 $\mu \mathrm{A}$ ) using a monopolar stimulating electrode (SNE-300; David Kopf Instruments). The strength of stimulation was adjusted to a level that was suitable to maintain locomotion for prolonged periods during the recording of spinal cord field potentials. The lowest threshold sites were located dorsal to the brachium conjunctivum in the vicinity of the cuneiform nucleus in four out of five animals in which the brainstem was processed for routine histology. In one case, the lowest threshold site was localized to an area immediately ventral to the brachium conjunctivum. The rhythmic activity of the hindlimb peripheral nerves (electroneurograms or ENGs) were used as monitors for fictive locomotion.

Spinal cord potentials and ENG activity were recorded during MLRevoked locomotion (Fig. 1A). The ENG activity was amplified, rectified, and low-pass filtered during each trial of locomotion before it was sampled continuously at $200 \mathrm{~Hz}$ by a Masscomp (MC563) computer. Spinal cord evoked potentials were recorded using two methods: (1) a monopolar silver ball electrode placed on the dorsal surface of the spinal cord near the dorsal root entry zone was used to record cord dorsum potentials along the spinal cord; and (2) a glass microelectrode with a tungsten filament was used to record intraspinal potentials. The spinal potentials were $\mathrm{AC}$ coupled $(0.1 \mathrm{~Hz}$ high-pass filtered; $10 \mathrm{kHz}$ low-pass filtered) and sampled at 5 or $10 \mathrm{kHz}$ for a period of 50 msec fullowing each MLR stimulus.

Spinal cord surface potentials. Cord dorsum potentials were sampled at regular $5 \mathrm{~mm}$ intervals across the lumbosacral segments (L3-S1) during bouts of fictive locomotion (Fig. $2 B$ ). The latency of onset and/ or of the peak of the different positive $(\mathrm{P} 1-4)$ and negative $(\mathrm{N})$ waves was measured from the averaged potentials recorded at each site (Fig. $1 C$ ). The amplitude of each wave was measured relative to either the baseline (for P1) or to the potential at its onset (for P2-4).

The amplitude modulation of the $\mathrm{P} 2$ and $\mathrm{P} 3$ waves during the fictive step cycle was also determined from measurements obtained from the electrode position showing the largest $\mathbf{P} 2$ or $\mathrm{P} 3$ wave. The step cycle was normalized and divided into equal time intervals or bins. The onset of each fictive step cycle was defined as the onset of activity of an ipsilateral flexor or extensor ENG. The cord dorsum traces recorded in each bin of the normalized step cycle were then averaged and the amplitude of each wave measured and subsequently plotted against the normalized step cycle. Averaged cord dorsum potentials were usually obtained from 10-15 step cycles, typically yielding 20-30 averages for each bin.

Intraspinal field potentials. Averages of intraspinal field potentials were produced as described above for the cord dorsum surface potentials. Frames containing spiking activity of single spinal neurons synchronized to the MLR stimulus were detected by a window discriminator in software and excluded from the averages. Latencies of intraspinal negative field potentials were calculated as follows: total latency was measured from the onset of the MLR stimulus; segmental latency was measured from the peak of the first potential recorded from the surface of the cord dorsum. The amplitude modulation of the negative field potentials during the fictive step cycle was determined from 


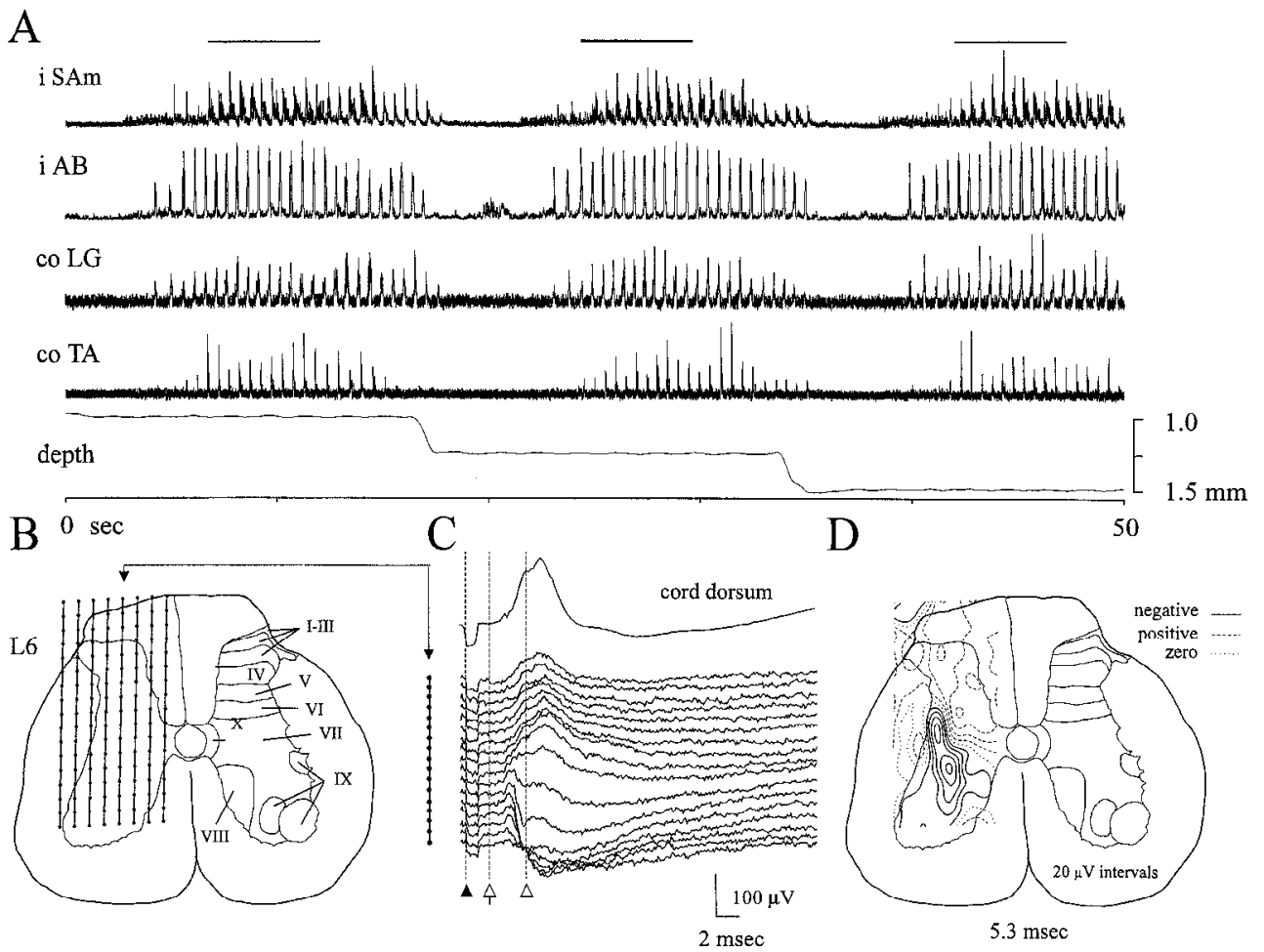

Figure 1. Method used to record spinal cord extracellular field potentials during MLR-evoked fictive locomotion and to generate isopotential contour maps. A, Fictive locomotion evoked by stimulation of the MLR. Bottom trace indicates depth of recording microelectrode measured from the surface of the spinal cord from the most medial track (first track in B). Lines (top) indicate the sampling periods for MLR-evoked spinal potentials at each depth. $B$, Matrix of microelectrode recordings made at $250 \mu \mathrm{m}$ intervals with each electrode track through the spinal cord. Microelectrode penetrations were made sequentially from medial to lateral with the zero depth for each track kept horizontal to the surface contact of the electrode in the most medial track. $C$, Triggered averages generated at each point of the matrix for the indicated track in $B$ during MLR evoked fictive locomotion. The amplitudes of the field potentials are measured at a specific latency(ies) (open arrowhead) following stimulation of the MLR (closed arrowhead). The latencies chosen correspond to the peak of the positive waves (P2-4) recorded from the cord dorsum surface potential (top trace) or to peaks of negativily observed in the intraspinal records (lower traces). Field potential amplitudes were determined relative to a level poststimulus baseline (arrow). $D$, Isopotential map of the amplitude of the intraspinal potentials recorded from each point of the matrix at a latency of $5.3 \mathrm{msec}$ following the MLR stimulus. Isopotential lines in this and other figures are drawn at intervals of $20 \mu \mathrm{V}$. SAm, medial sartorius; $A B$, anterior biceps; $L G$, lateral gastrocnemius; T'A, tibialis anterior; $i$, ipsilateral; $c o$, contralateral. MLR stimulation parameters: $220 \mu A$, $19.5 \mathrm{~Hz}, 1.0 \mathrm{msec}$ duration.

measurements obtained at maximum current sinks in some experiments (see Spinal Cord Surface Potentials, above).

Isopotential maps. The intraspinal microelectrode recordings were made at the evenly spaced coordinates of a matrix (Fig. $1 B$ ). The matrix was obtained by making vertical (or near vertical) penetrations through the spinal cord and recording MLR-evoked potentials in steps of 250 $\mu \mathrm{m}$. Tracks were equally spaced (every $250 \mu \mathrm{m}$ ) and were made successively from a point $250 \mu \mathrm{m}$ lateral to the midline.

The matrix values were used to generate isopotential contour maps of MLR-evoked potentials. Isopotential maps were generated in two steps: (1) calculation of isopotential lines from the intraspinal potentials and (2) overlay of the histological outline onto the coordinates of the matrix. For the first step, a computer average was produced of MLRevoked potentials sampled for each coordinate of the matrix (Fig. $1 B, C$ ) during MLR-evoked locomotion (Fig. 1A). The amplitude of the potential at a specified latency after the MLR stimulus was measured for each coordinate. The latencies chosen for measurement of the intraspinal potentials corresponded to the peak of each positive wave (P1-4) from the cord dorsum surface potential or to peaks of negativity observed from the intraspinal records. Using a bicubic interpolating spline function (Späth, 1974), a matrix of higher resolution was generated by fitting a continuous surface through the given points over the entire area of the matrix. Regions of equal potential were then connected to form isopotential lines (Fig. $1 D$ ). As a result, the isopotential lines do not necessarily pass through the actual recording coordinates. For the second step, camera lucida drawings of cross sections of the spinal cord containing the reconstructed electrode tracks were entered into the computer using a digitizing tablet. The most dorsal or ventral points of the most medial and lateral electrode tracks were identified, and the contour mapping program then fitted the corners of the matrix to the points identified on the computer image. The most dorsal point was identified from the surface of the spinal cord, the most ventral point from a lesion made with the microelectrode at the end of the mapping series in each segment (L4-7).

Two types of contour maps were generated. The first was obtained from averages of MLR-evoked potentials spanning the entire step cycle and, therefore, included the responses obtained from each point of the matrix during both flexion and extension (50-100 samples/average). The second was obtained from averages of MLR-evoked potentials collected from each point of the matrix during the flexion or extension phase of the step cycle as defined by the activity of the respective nerves (20-60 samples/average).

\section{Results}

The results described in this study were obtained from a total of 16 cats that exhibited rhythmic ENG activity typical of MLRevoked fictive locomotion (Fig. 1A). In all experiments, the MLR stimulus evoked bilateral locomotor activity.

\section{MLR-evoked cord dorsum potentials}

Profile along the lumbosacral segments. The cord surface potential evoked by stimulation of the MLR and recorded from the surface of the caudal lumbar spinal cord consisted of four positive $(\mathrm{P})$ waves (Figs. $1 C, 2 A$ ) in all experiments. The amplitude of these potentials depended upon the site of the recording elec- 
Figure 2. Profile of MLR-evoked cord dorsum potentials recorded along lumbosacral segments L3-S1 during fictive locomotion. $A$, Rostral-caudal distribution of cord dorsum potentials recorded at the dorsal root entry zone at the indicated levels of the spinal cord. The four positive waves (P1-4) are numbered. $B$, Cord dorsum potentials recorded at various medial-lateral locations of the L5 segment. The middle aspect of the dorsal columns, the dorsal root entry zone, and the lateral funiculus are indicated as sites $a-c$, respectively. $C$, Raw (dashed lines) and averaged (solid lines with open circles, with mean and standard error) amplitudes of each P-wave ( $n=13$ animals) measured at each segmental level expressed as a percentage of the maximum peak amplitude. $N$, Negative cord dorsum potential. MLR stimulation strengths: $A, 220 \mu \mathrm{A}, 19.5 \mathrm{~Hz}, 1 \mathrm{msec}$ duration; $B, 190 \mu \mathrm{A}, 15 \mathrm{~Hz}, 1 \mathrm{msec}$ duration.
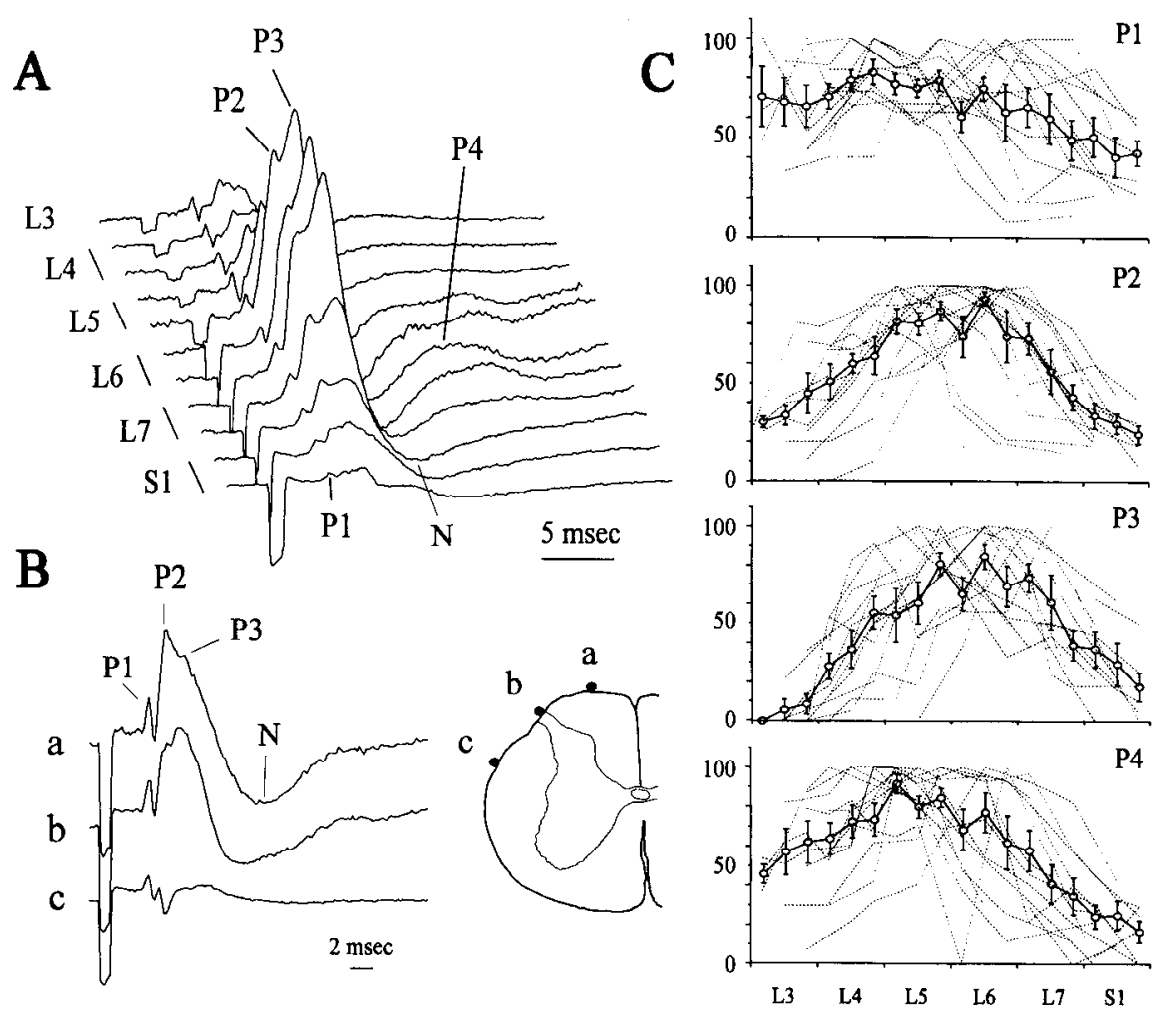

trode and were found to be largest when recorded from the middle of the dorsal columns or from the dorsal root entry zone (Fig. 2B). At more lateral locations the P2 and P3 components of the cord surface potential disappeared and were replaced by a negative wave. This was in contrast to the P1 wave, which retained its basic shape when recorded from the lateral funiculus. The P1 wave was the earliest signal to be recorded following the MLR stimulus in 12 of 16 experiments. However, in four experiments a smaller potential, possibly a volley, was observed immediately prior (within $1.0 \mathrm{msec}$ ) to the P1 wave. The P2 wave was always larger than the P1 wave. The P3 wave often peaked at a more positive level than the P2 wave (see Figs. $1 A$, $2 A, 4 B$ ), although less positive peaks were not infrequent (Figs. $3 A, 4 A$ ). The relative amplitudes of the $\mathrm{P}$-waves recorded along the lumbosacral spinal cord (from L3 to S1) were measured in 13 experiments (Fig. 2C). P2, P3, and P4 were largest in the L5-L6 scgments. The P1 wave was largest in the more rostral segments and decreased in amplitude in more caudal segments.

Latencies of onset and peak of cord dorsum potentials. The latencies of onset and peak of the various $\mathrm{P}$-waves were measured at the L5/6 segment where they had their maximum amplitude. The minimum volley/P1 peak latency $(3.4 \mathrm{msec})$ can be attributed to the arrival of the descending volley if the synaptic delay within the caudal brainstem is assumed to be 1 Insec (Orlovsky, 1969), and the most rapidly conducting fibers in this pathway have a conduction velocity in excess of $120 \mathrm{~m} / \mathrm{sec}$. Similarly, longer latency P1 waves (up to $4.8 \mathrm{msec}$ ) can be attributed to fibers with conduction velocities approximating 80 $\mathrm{m} / \mathrm{sec}$. Subsequent P-waves appear to be produced by sequential synaptic activation; e.g., the onset of the P2 wave occurs approximately $0.8 \mathrm{msec}( \pm 0.5 \mathrm{msec}, \mathrm{SD})$ after the peak of the volley/P1 potential. The onset of P3 occurs $0.6 \mathrm{msec}$ after the peak of P2 and with a mean segmental latency of $2.4 \pm 0.5$ msec. Both P2 and P3 peaked within $1 \mathrm{msec}$ of their onset.
The latency of onset for the $\mathrm{P} 4$ wave was more difficult to determine since it followed an extended negative wave, the decay of which influenced the measurement of the P4 onset latency. Therefore, the latency of the peak was measured. These latencies were found to vary considerably $(16.8 \pm 5.3 \mathrm{msec})$.

Evidence for a relationship between MLR-evoked cord dorsum potentials and fictive locomotion. Two lines of evidence indicate that the MLR-evoked cord dorsum potentials are related to locomotor processes. First, the amplitude of the MLR-evoked cord dorsum $\mathrm{P}$ waves ( $\mathrm{P} 2-4)$ increased concomitant with the appearance of fictive locomotion (Fig. 3). Second, the MLRevoked cord dorsum potentials (P2-4) were rhythmically modulated during the fictive step cycle. This amplitude modulation was strongly related to the phase of the step cycle. This is illustrated in Figure 4 for two different experiments. In Figure $4 A$, the P2 wave was largest at the onset of extension, whereas the P3 and P4 waves were largest during flexion. The modulations were different for the experiment illustrated in Figure $4 B$, where the $\mathrm{P} 2$ wave was largest during flexion and the P3 and P4 waves peaked both in flexion and extension. The P-waves were modulated in every experiment by at least $15 \%$, and peak amplitudes were observed in either or both phases of the step cycle. The P2 wave was approximately equally modulated during flexion (six experiments) and extension (seven experiments), or both (three experiments). P3 was largest during flexion in 10 experiments and showed peaks in both phases in 6 experiments. P4 showed a similar pattern of modulation (flexion, seven experiments; extension, one experiment; both, eight experiments). Differences between experiments may be due to differences in rostrocaudal placement of the electrode and to its placement relative to the various subsets of interneurons beneath. It is unlikely that the same sets of interneurons have different phase relationships with the locomotor cycle in different animals. 
A $\quad$ L5/6 cord dorsum potential

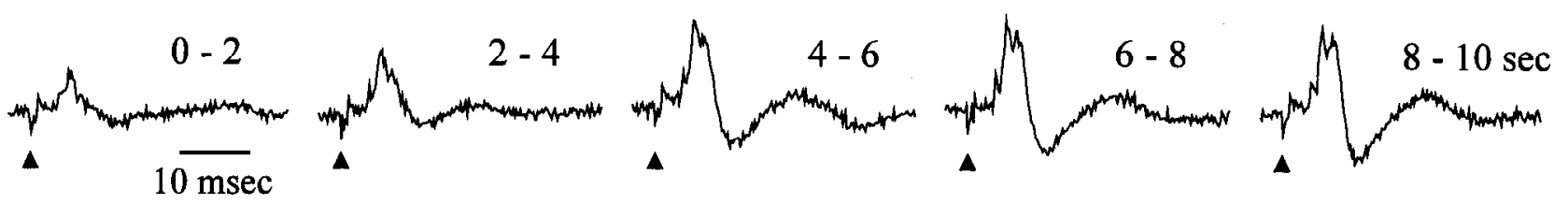

B
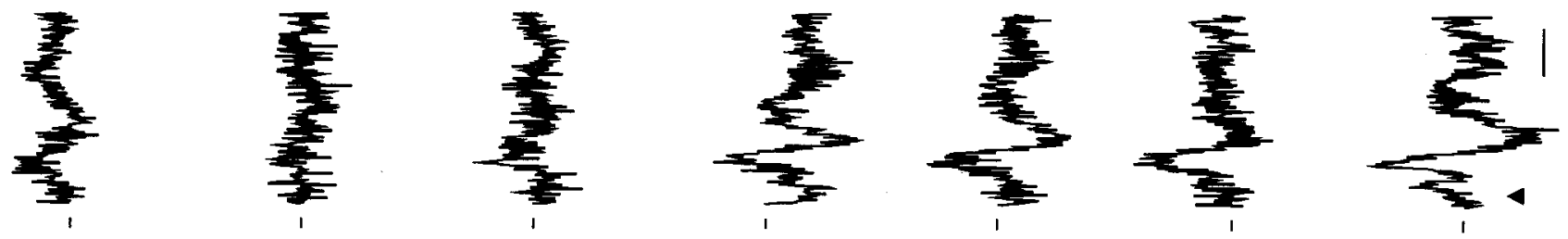

L SA

L SMAB

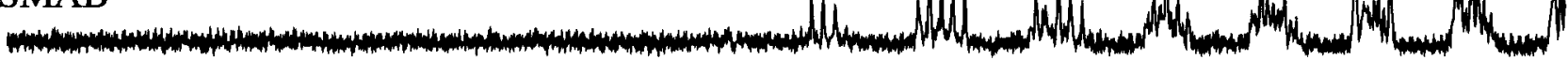
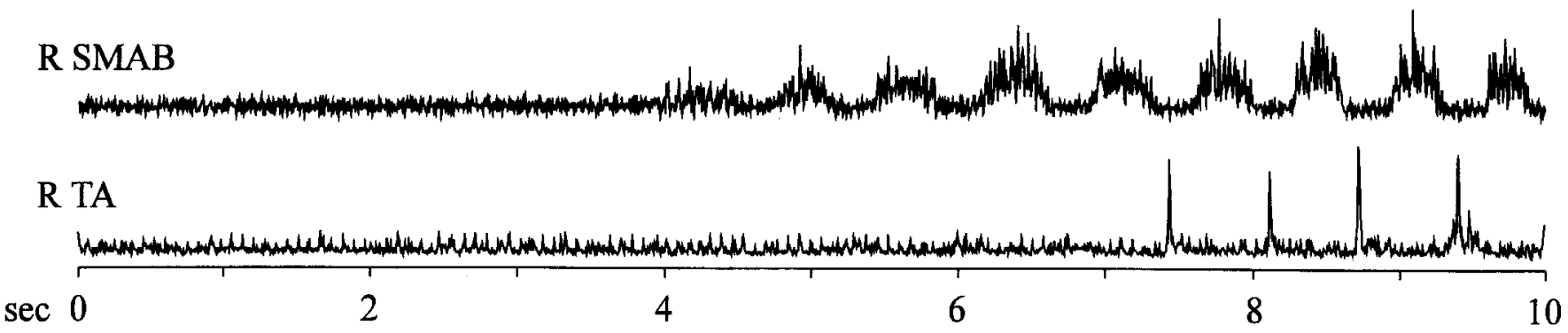

Figure 3. Changes in L5-6 cord dorsum surface potentials evoked by stimulation of the MLR prior to and during fictive locomotion. The MLR was stimulated at a strength of $160 \mu \Lambda$, throughout $(13 \mathrm{~Hz}, 1.0 \mathrm{msec}$ duration). A, Averages $(n=26)$ of right cord dorsum potentials (ipsilateral to the stimulated MLR) for the indicated time periods throughout the trial. $B$, Raw traces of MLR-evoked cord dorsum surface potentials recorded at the indicated periods prior to and during MLR-evoked locomotion. ENGs of the indicated nerves are shown beneath. The timing of the MLR stimulus is indicated by the closed arrowheads at the botton of the averaged or to the right of the raw cord dorsum potentials. $S A$, sartorius; $S M A B$, semimembranosus/anterior biceps; $T A$, tibialis anterior; $L$, left (contralateral); $R$, right (ipsilateral).

\section{MLR-evoked intraspinal field potentials and isopotential maps}

Intraspinal field potentials and the subsequent isopotential maps were generated from data collected in six experiments (two L4 maps, four L5 maps, five L6 maps, and one L7 map). Both positive and negative field potentials were observed in all segments examined. Negative field potentials were observed in laminae VI through $\mathrm{X}$. In contrast, positive field potentials predominated in the dorsal horn.

Negative field potentials. Stimulation of the MLR-evoked negative field potentials in laminae VI-X of the L4-L7 spinal segments (Figs. 5, 6). In many experiments, two negative field potentials were observed from the same or similar recording sites in laminae VII and VIII and are designated as "early" and "late" potentials.

Laminae VI/VII. The earliest field potential evoked by electrical stimulation of the MLR was localized to lamina VII and occasionally to the lateral border region between laminae VI and VII. This field potential occurred first in the lateral aspect of laminae VI/VII and progressively later towards the midline (Fig. $5 A, C:$ traces $\mathrm{b}, \mathrm{c}$ ). This field potential was also earliest in the most rostral (L4) segment and was observed slightly later in the more caudal segments as the volley was propagated more caudally (Fig. 5A,C: trace b). Most early laminae VI/VII field potentials began within $1.0 \mathrm{msec}$ of the peak of the volley/P1 wave and were considered to be evoked by monosynaptic activation of interneurons from the descending fibers (Fig. 7). The "early" laminae VI/VII field potential was often maximal during the peak of the $\mathrm{P} 2$ cord dorsum potential (Figs. $1 C, 5 A-C$ ). The mean segmental and total latencies of onset of the early laminae VI/VII field potentials were $0.9 \pm 0.7$ and $4.4 \pm 0.9 \mathrm{msec}$, respectively. The segmental latency was thus similar to that observed for the onset of the P2 wave.

A second or "late" laminae VI/VII field potential was observed 1.5-3.4 msec following the earliest VI/VII field potential in the L4-6 spinal segments, indicating that some neurons at the same location may have been depolarized a second time following stimulation of the MLR (Figs. 5, 6). The onset of this potential occurred approximately at the onset of the P3 cord dorsum potential and had a latency of $6.6 \pm 0.8 \mathrm{msec}$ after the MLR stimulus. The segmental latencies of later laminae VI/VII field potentials (Fig. 7) are primarily indicative of a tri- or polysynaptic linkages $(3.0 \pm 0.5 \mathrm{msec})$, although the possibility 
A

Figure 4. Modulation of cord dorsum surface potentials during MLR-evoked fictive locomotion. ENG data for two different experiments are indicated separately in $A$ and $B$. The averaged cord dorsum potentials (middle panel) are sorted according to the occurrence of each evoked potential during the normalized step cycle (top panel). Each trace is recorded over a $30 \mathrm{msec}$ period. Lower panels indicate the relative amplitude of the P2-4 waves sorted according to their occurrence in the step cycle. Values are expressed as a percentage of the maximum peak amplitude. The flexion $(f)$ and extension $(e)$ phases of the step cycle are indicated. $S A$, sartorius; $S A a$, sartorius anterior; $A B$, anterior biceps; $G S$, gastrocnemius; $i$, ipsilateral to side of MLR stimulation and cord dorsum recording. MLR stimulation strengths: $A, 160 \mu \mathrm{A}, 25 \mathrm{~Hz}$, 0.5 msec duration; $B, 160 \mu \mathrm{A}, 16 \mathrm{~Hz}$, $1 \mathrm{msec}$ duration.
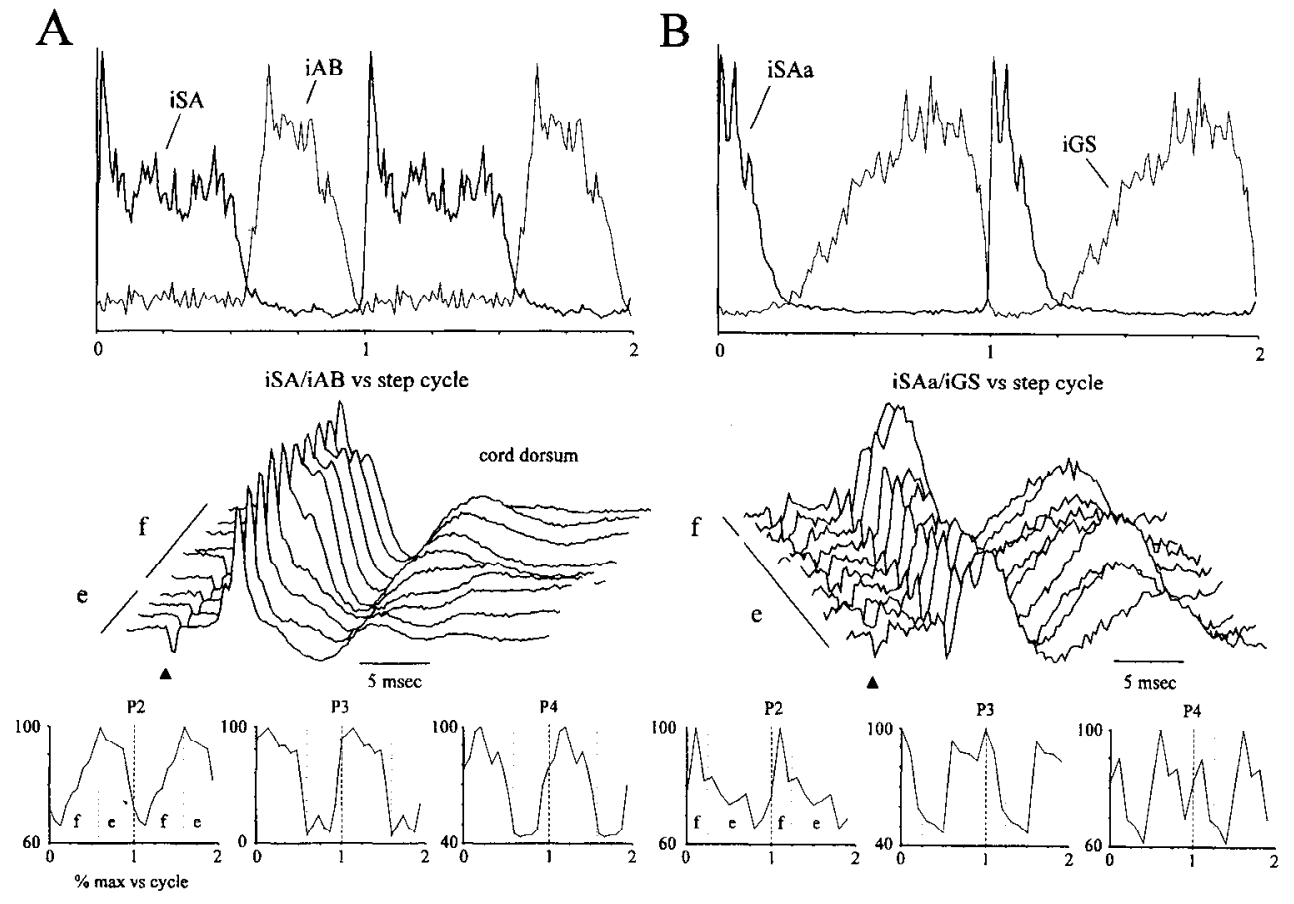

that these are evoked by slower conducting descending fibers cannot be excluded. In some cases, even later lamina VII negative waves that peaked at the same time as the $\mathrm{P} 4$ cord dorsum potential could be seen (Fig. 6A).

In experiments where multiple isopotential maps were made, the largest lamina VII negative field potentials were found in the L5/6 segments. The amplitude of the "early" and "late" field potentials ranged from $44-180 \mu \mathrm{V}$ (mean, $96 \pm 43 \mu \mathrm{V}$ ) and 31-230 $\mu \mathrm{V}$ (mean, $80 \pm 61 \mu \mathrm{V}$ ), respectively.

Isopotential maps were generated to provide a graphical representation of the probable locations of the neurons producing the laminae VI/VII field potentials (Figs. 6,8 ). Single or multiple current sinks could be found in these laminae (see Figs. 6, 8). The relative amplitudes of the different current sinks could differ substantially (Fig. 6A).

Lamina VIII. Short-latency, MLR-evoked field potentials were observed in lamina VIII of the L4-7 spinal segments (Figs. 5A$C, 6 A)$. The segmental latency of the earliest lamina VIII potentials showed mono- and disynaptic linkages (Fig. 7) ranging between 0.2 and $3.4 \mathrm{msec}$ from the peak of the volley/P1 potentials $(1.4 \pm 0.8 \mathrm{msec}$, mean and SD). The onset of the earliest lamina VIII field potentials was usually at or just after the onset of the P2 cord dorsum potential and the onset of the earliest laminae VI/VII negative field potentials (Figs. $5 A, C ; 6 A$ ). The latency from the time of the MLR stimulus was $5.0 \pm 1.0 \mathrm{msec}$. The monosynaptic lamina VIII field potentials peaked at the apex of the $\mathrm{P} 2$ or P3 cord dorsum potentials, whereas the disynaptic VIII fields peaked after the apex of the P3 wave. The latencies of onset of the earliest lamina VIII field potentials in the most rostral segments were either shorter or approximately the same as those occurring in more caudal segments. Where the latencies are similar, a slowing of conduction in the terminal branches in the rostral segments may be the explanation.

A second or "late" lamina VIII negative field potential was sometimes observed $2.1-3.2 \mathrm{msec}$ following the first lamina VIII field potential in the L4-6 spinal segments. The locations of the current sinks of these later lamina VIII field potentials were the same or similar to the early lamina VIII potentials, indicating that some neurons at the same location may have been depolarized a second time following stimulation of the MLR. Alternativcly, this depolarization could be due to activation of different sets of interneurons in a similar location. The onset of the late lamina VIII field potential usually occurred at the onset or peak of the P3 cord dorsum potential and always peaked after the apex of the P3 wave. The total latency to onset was $6.7 \pm 0.7$ msec. The segmental latencies of the late lamina VIII field potential (Fig. 7) are indicative of a polysynaptic linkage (3.5 \pm 0.3 msec). In some cases, very long latency lamina VIII negative potentials that peaked at the same time as the $\mathrm{P} 4$ cord dorsum potential could be seen (Fig. $6 \mathrm{~A}$, trace d).

The early lamina VIII field potentials were approximately the same amplitude as the lamina VII field potentials (mean, $113 \pm$ $75 \mu \mathrm{V}$; range, $31-290 \mu \mathrm{V}$ ). The largest early field potentials were found in the L4/5 segments. The late lamina VIII field potentials were generally smaller (mean, $55 \pm 15 \mu \mathrm{V}$; range, 40-77 $\mu \mathrm{V}$ ).

Isopotential maps of lamina VIII negative field potentials are illustrated in Figures 6 and 8. In some cases, summation with the lamina VII field potentials prevented a clear focus of negativity in lamina VIII.

Lamina IX. Negative field potentials were observed within lamina IX of the ventral horn. These field potentials characteristically exhibited a rapid onset and gradual decay. The segmental latency for the lamina IX field potentials ranged from 1.5 to $3.4 \mathrm{msec}$ (Fig. 7), with a mean of $2.2 \pm 0.5 \mathrm{msec}$, the earliest ones possibly being evoked disynaptically and the later ones showing trisynaptic (or polysynaptic) linkages. The onset of the lamina IX field potential was usually around the peak of the P2 or onset of the P3 cord dorsum potential and had a total latency of $5.8 \pm 0.8 \mathrm{msec}$. The lamina IX field potential usually peaked after the apex of the $\mathrm{P} 3$ cord dorsum potential (Fig. $5 B$ ) although some potentials peaked at the apex of the $\mathrm{P} 3$ wave (Figs. $5 C$, $6 A$ ). The peak amplitude of the lamina IX field potential ranged from 66 to $380 \mu \mathrm{V}$ and was the largest MLR-evoked negative 


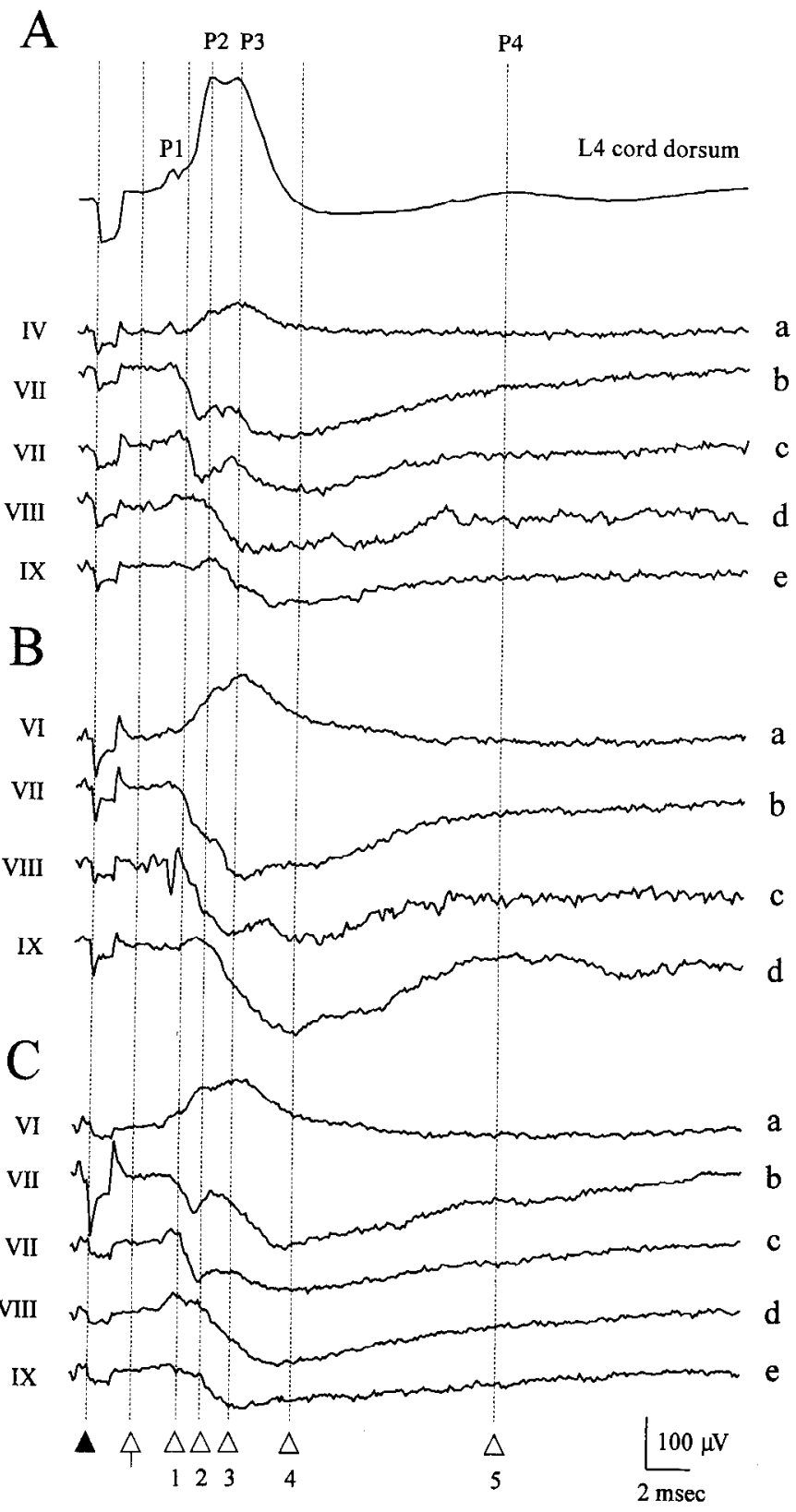

field potential (mean, $152 \pm 98 \mu \mathrm{V}$ ). Small, longer latency field potentials were occasionally observed superimposed upon the gradual decay of the first negative field potential. A second wave of negativity that peaked at the apex of the P4 cord dorsum potential was observed in one experiment. Isopotential maps illustrating lamina IX field potentials are shown in Figures $6 \mathrm{~A}$ and 8.

Lamina $X$ and medial lamina VII. Stimulation of the MLR also evoked short-latency negative field potentials in a region near the central canal of the L5 and L6 segments of the spinal cord. The field potentials were localized to either lamina X or to the adjacent medial aspect of lamina VII. This was observed in three of the nine isopotential maps made of the L5/6 spinal segments. The segmental latency of these field potentials ranged from 1.5 to $3.2 \mathrm{msec}$ (mean, $2.4 \pm 0.9 \mathrm{msec}$ ). They were evoked di-, tri-, and polysynaptically, assuming that they were evoked by the fastest conducting reticulospinal neurons (Fig. 7). The onset of these negative field potentials occurred at or between

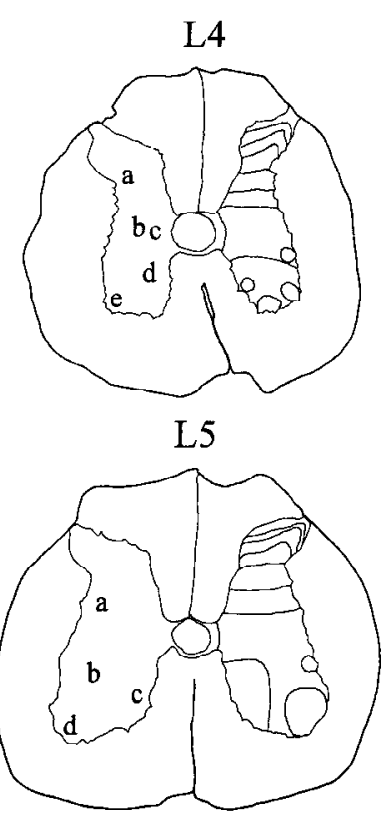

Figure 5. Averaged cord dorsum (top trace) and intraspinal field potentials (lower traces) recorded in the L4 $(A)$, L5 $(B)$, and L6 $(C)$ spinal segments during fictive locomotion evoked by stimulation of the ipsilateral MLR (220 $\mu \mathrm{A}, 19.5 \mathrm{~Hz}, 1.0 \mathrm{msec}$ duration). Location of the recording sites for all traces are indicated in the spinal cord reconstructions to the right. Negative $(N)$ field potentials were recorded in laminae VII-IX in all segments as indicated to the left of each trace. Positive field potentials were observed throughout the dorsal horn in all segments and are indicated in trace $a$ in $A-C$ for laminae IV and VI. Isopotential maps (see Fig. 8) were made at the indicated (numbered) latencies (open arrowheads) following the MLR stimulus (solid arrowhead). Arrow, baseline reference point. Amplitude measurement latencies of lines 2,3 , and 5 are measured at the peaks of the P2, P3, and P4 cord dorsum positive potential. These and other latency measurements (lines 1 and 4) may also correspond to the latencies of the peaks of various intraspinal negative field potentials. See text for further details. Calibration: $100 \mu \mathrm{V}$ (for AC traces), 2 msec.

the peaks of the P2 or P3 cord dorsum potentials-at the same time as or slightly later than the lamina IX field potential (the mean total latency for the lamina $X$ field potentials being $5.7 \pm$ $0.5 \mathrm{msec}$ and, thus, similar to the lamina IX field potentials). The lamina $X$ field potentials peaked after the apex of the P3 cord dorsum potential. The peak amplitude ranged from 92 to $130 \mu \mathrm{V}$ (mean, $107 \pm 20 \mu \mathrm{V}$ ). Thus, the lamina $\mathrm{X}$ field potentials were as large or larger than all but the lamina IX MLRevoked negative field potentials. An isopotential map illustrating a lamina $\mathrm{X}$ field potential is shown in Figure $6 B$.

Distribution of field potential foci (current sinks) in the lumbar segments. Figure 9 summarizes the distribution of all field potential foci detected in field potential maps. The current sinks were confined to laminae VI-X. Monosynaptic field potentials were primarily observed in laminae VI, VII, and VIII. Disynaptic field potentials were primarily observed in lamina VIII in the L6/7 segments and in the motor nuclei (lamina IX) of all segments. A second wave of excitation (tri- and polysynaptic seg- 
A
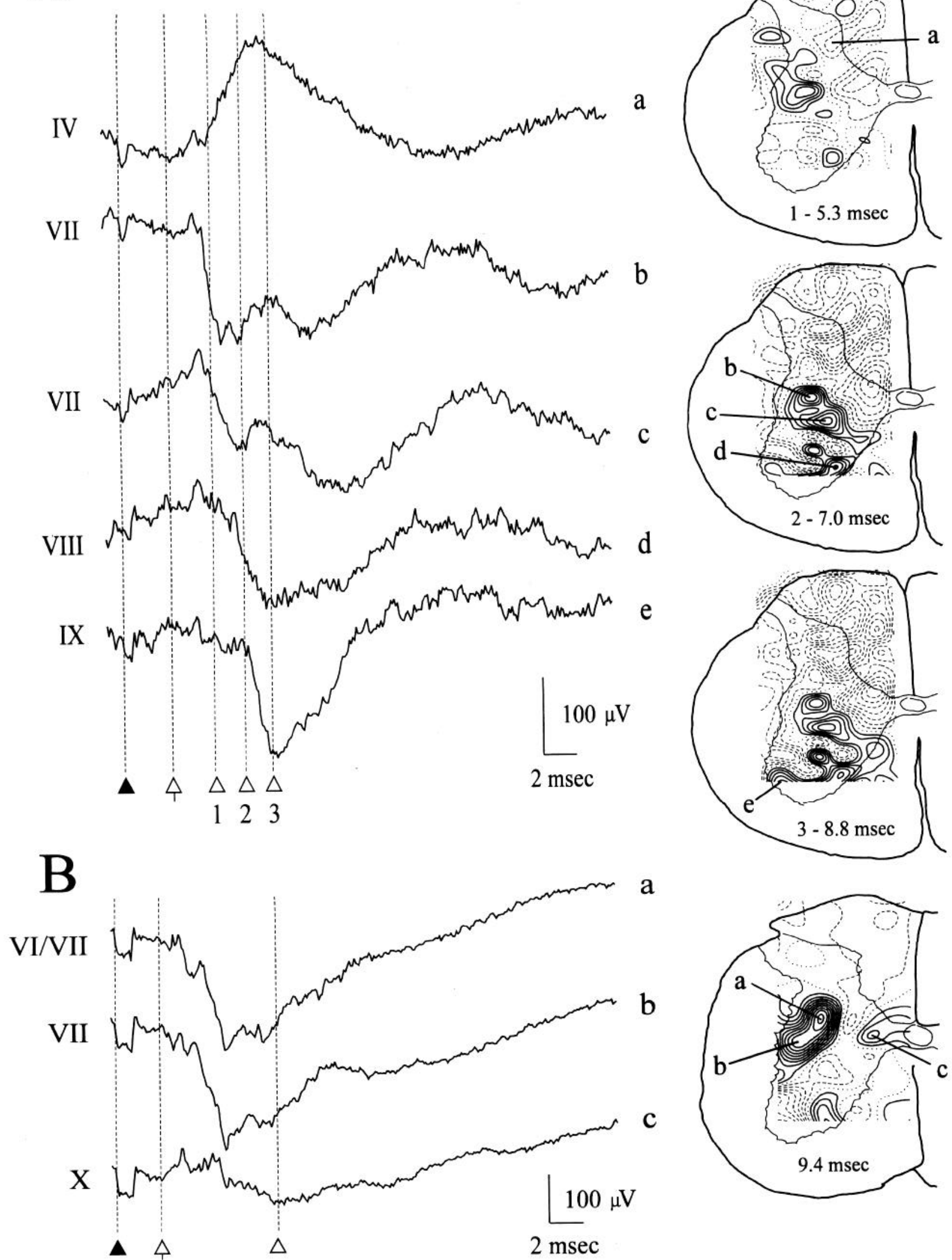
mental latencies) was observed in laminae VI-VIII in all segments.

Modulation of negative intraspinal field potentials during fictive locomotion. Isopotential maps were made of MLR-evoked field potentials occurring during the flexor or extensor phase of the step cycle, and examples of these are illustrated in Figure 10. Slight differences in the overall amplitude and location of the early and late current sinks were observed during flexion and extension, indicating that the excitability of the neurons in these areas was modulated during the step cycle. This is further evident in Figure 10 (lower panels), which show the amplitude modulation of the current sinks illustrated in the upper panels relative to the phase of the step cycle. Both single (Fig. 10B) or double (Fig. 10A) peaks (during flexion and/or extension) were observed for the different field potentials. A total of 11 negative foci such as those illustrated in Figure 10 were analyzed to determine any modulation during the step cycle. In all of these cases, discernable modulation was observed. This may be interpreted as evidence that the evoked responses are produced in cells that are part of the locomotor circuitry. In general, the locations of foci of negative potentials evoked during flexion were similar to those of the foci evoked during extension, indicating that flexor- and extensor-related neurons are intermingled.

Positive field potentials. Stimulation of the MLR also evoked positive field potentials throughout the dorsal horn of the L4 L7 spinal segments (Figs. 1, 5, 6). In general, the shape of these potentials resembled the cord dorsum potentials recorded more dorsally. Thus, foci of positivity were generally largest during the P3 wave (and occasionally the P2 wave) of the cord dorsum potential. Foci of positivity were found most frequently in laminae III-VI and rarely in lamina VII (Figs. 6, 8).

\section{Discussion}

This study demonstrates that cord dorsum and intraspinal potentials evoked by stimulation of the MLR may be useful for lucating neurons involved in locomotion. The modulation of the cord dorsum and intraspinal negative field potentials in phase with the locomotor cycle, along with the fact that the cord dorsum potentials increase in amplitude coincident with the appearance of locomotion, suggest that the responsible interneurons are part of the locomotor circuitry. It is also possible that the modulation is due, at least in part, to activity in interneurons that receive input from the locomotor circuitry without having a direct influence on the ncural processes involved in locomotion.

Flectrical stimulation of the MLR appears to activate more than one population of spinal neurons, since negative field potentials were distributed through laminae VI-X of the lumbar spinal cord. This suggests that populations of neurons that form different components of the locomotor circuitry (such as excitation of extensor vs. flexor motoneurons, interlimb coordination, etc.) receive input from the MLR.

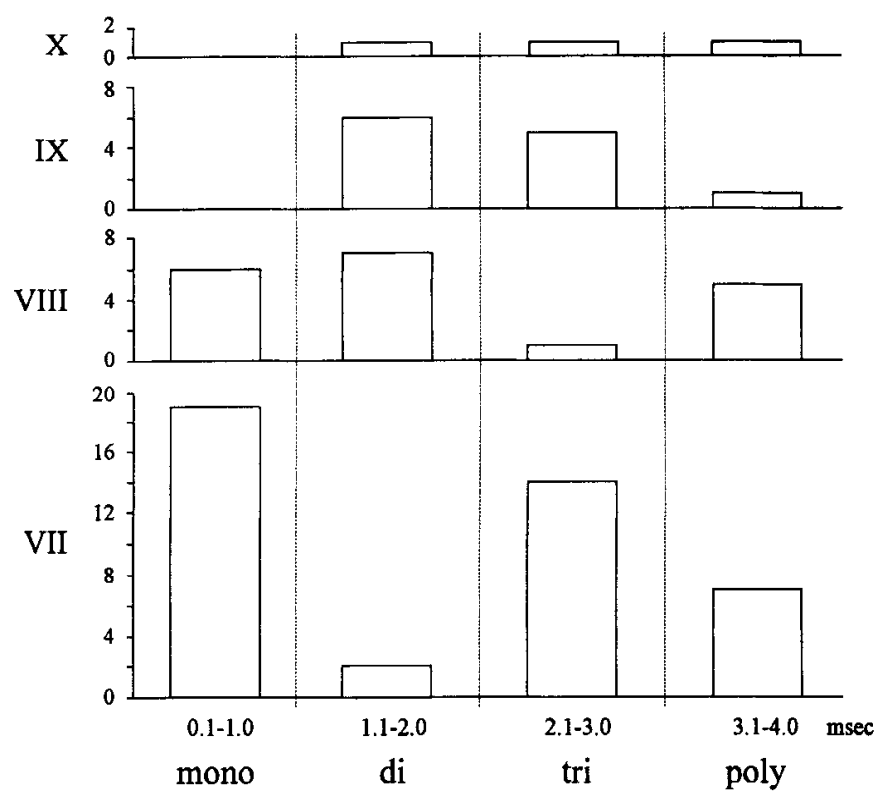

Figure 7. Scgmental latencies of negative field potentials measured from the L4-7 spinal segments. Latencies were measured from the peak of the first recorded cord dorsum potential to the onset of the field potential in the various spinal laminae. Latencies for monosynaptic excitation are considered to be up to $0.9 \mathrm{msec}$ (allowing for a conduction time from the arrival of the volley to the terminal of the descending fiber of $0.1-0.6 \mathrm{msec}$ and a synaptic delay of $0.3 \mathrm{msec}$ ). Each additional interneuronal relay would require a delay of about $0.2 \mathrm{msec}$ between the onset of the interneuronal epsp and the action potentials that they evoke, $0.2-0.6 \mathrm{msec}$ for conduction of the action potential to the synapse and $0.3 \mathrm{msec}$ for another synaptic delay; i.e., approximately $0.7-$ $1.1 \mathrm{msec}$. Segmental linkages are indicated at the bottom of the histogram. Ordinate, number of observations.

The results described here suggest that the interneurons related to the initiation of locomotion are most numerous in the L4L6 spinal segments (see Fig. $2 C$ ). This is consistent with the results of Grillner and 7angger (1979), who showed that the ability to initiate locomotion in spinal animals is lost after spinal transections below caudal L5. Furthermore, it is consistent with the results of Deliagina et al. (1983), who provided evidence for the possibility that the L3-L5 segments are the "leading" ones for the production of rhythmic activity in the lumbar spinal cord. On the other hand, Viala et al. (1988) found that locomotion increased metabolism of rabbit spinal cord cells in the intermediate gray matter from L6 to S1. It should be noted, however, that the animals in this latter study were spinalized and that locomotion was induced by injections of L-DOPA. Further experiments are needed for a direct comparison of the two preparations. Barajon et al. (1992) examined c-fos expression in the lumbosacral enlargement induced by scratching and found that activity-dependent labcling using this marker was abundant in the L7 and S1 segments. They did not describe c-fos expression

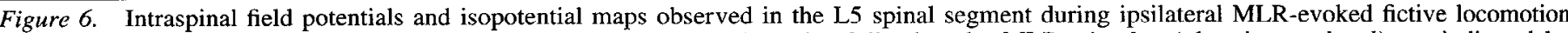

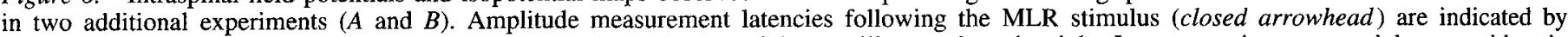

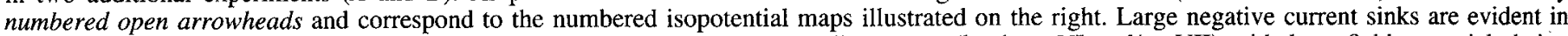

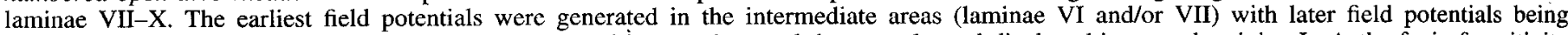

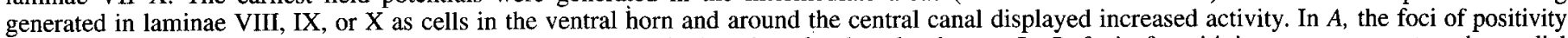

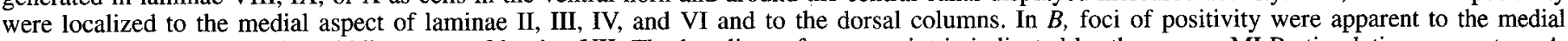

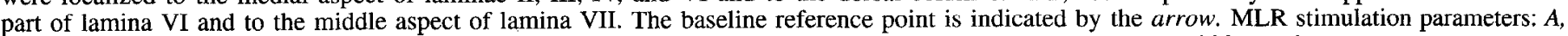
$220 \mu \mathrm{A}, 17 \mathrm{~Hz}, 0.5 \mathrm{msec}$ duration; $B, 160 \mu \mathrm{A}, 19 \mathrm{~Hz}, 1.0 \mathrm{msec}$ duration. Calibration: $A, 100 \mu \mathrm{V}, 2 \mathrm{msec} ; B, 200 \mu \mathrm{V}, 2 \mathrm{msec}$. 


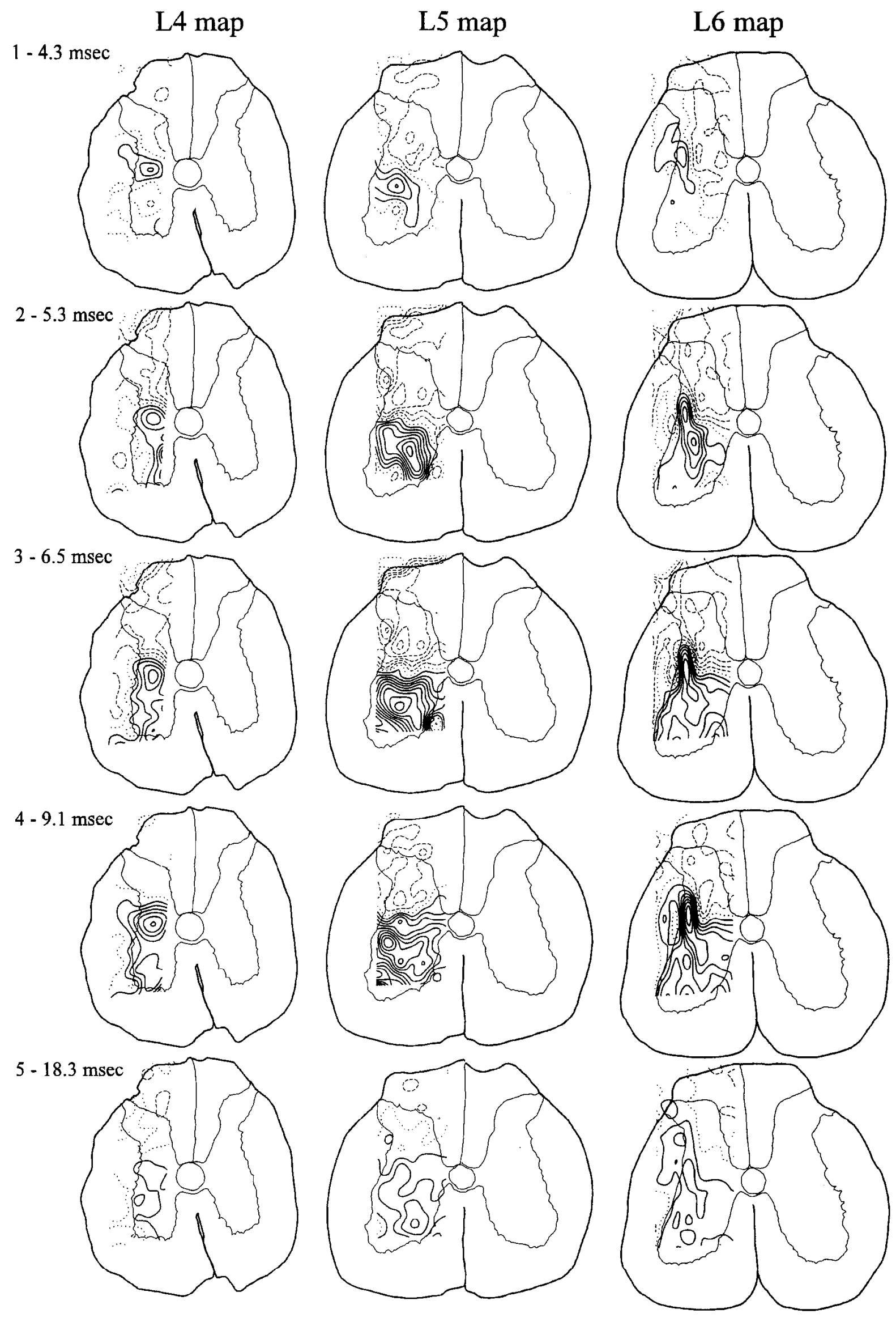


in more rostral segments, however. Other evidence favoring concentration of rhythm generating elements in the rostral segments of the lumbosacral enlargement comes from work on turtle (Mortin and Stein, 1989) and chick spinal cord (Ho and O'Donovan, 1993).

Figure 9 sumnarizes the laminar distribution of MLR-evoked negative field potential foci detected with the isopotential mapping procedure used here. The cells that receive the earliest input appear to be concentrated in lamina VII and, to a lesser extent, in lamina VIII. Presumptive disynaptic responses were observed largely in laminae VIII, IX, and X. What appears to be "rebound" excitation of the same cells activated earlier can be seen at trisynaptic and later latencies in laminae VII, VIII and also in lamina IX. Skinner and Willis (1970) used cord dorsum and isopotential mapping methods as a means to detect the locations of interneurons activated by stimulation of the ventrolateral white matter. The cord dorsum potentials and intraspinal field potentials that they detected were similar to those evoked by stimulation of the MLR. This is consistent with the observation (Steeves and Jordan, 1980) that locomotion is initiated from the MLR by a pathway that descends through the ventrolateral funiculus of the spinal cord.

There is considerable evidence in the literature supporting the notion that cells in the regions displaying negative field potential foci are involved in rhythmic motor activity. The negative field potential foci observed here partly overlap the laminar distribution of c-fos-labeled cells in decerebrate cats in which unilateral scratching was induced (Barajon et al., 1992). In this case, most c-fos-labeled cells were localed in the dorsolateral part of the ventral horn and in the intermediate zone (lamina VII), with some labeled cells in the medial part of lamina VII and in lamina VIII. C-fos expression produced by fictive locomotion in decerebrate cats revealed labeled cells largely in lamina VII, especially the medial part, in lamina VIII, and in lamina X (Dai et al., 1990). Jasmin et al. (1994) used a Rota-Rod walking task to induce c-fos expression in rats. They did not describe the rostrocaudal distribution of the labeling in their experiments, but most of the labeling occurred in the dorsal horn. Ventral horn labeling was observed in lamina VII and lamina X of the cervical and lumbar spinal cord. These authors used a deafferentation strategy to reveal the sensory components of the c-fos expression, and this procedure dramatically reduced labeling in both the dorsal and ventral horns. Labeling in the area around the central canal persisted, however. Kjaerulff et al. (1994) used sulfrhodamine labeling to determine the distribution of cells in the neonatal rat spinal cord, which are activated during chemically induced fictive locomotion in vitro. Iabeled cells that are likely part of the motor component of locomotor movements were localized in the intermediate zone and around the central canal. The uptake of 2-deoxyglucose during L-DOPA-induced fictive locomotion in low-spinal rabbits was found to be mainly localized in the intermediate gray matter along L6-S1 (Viala el al., 1988), although individual cells cannot be detected with this method.

Transneuronal labeling has been used to localize last-order interneurons that are active during locomotion in intact cats (Alstermark and Kummel, 1986; Jankowska, 1986; Jankowska and Skoog, 1986), and they were confined to laminae V-VII, ipsilateral to the filled motoneurons and lamina VIII, contralaterally. Injections of fluorescent microspheres into hindlimb motor nuclei (Hoover and Durkovic, 1992) revealed a similar distribution of retrogradely labeled interneurons, but labeled neurons were also observed in lamina $\mathrm{V}$ and lamina $\mathrm{X}$. Transneuronal labeling with pseudorabies virus injections in the rat medial gastrocnemius muscle was observed in laminae I, II, IV-VIII, and X (Rotto-Percelay et al., 1992). Preliminary results (Noga et al., 1987b) using transsynaptic labeling with WGA-HRP in the MLR-evoked locomotion preparation revealed last-order interneurons projecting to anterior biceps motoneurons in the ipsilateral intermediate gray matter (laminae VI, VII, and X) and in contralateral lamina VIII.

The physiological roles of most of the cells in the areas of negative field potentials evoked by stimulation of the MLR have not yet been established. Results from ongoing studies (Jordan and Noga, 1991; Carr et al., 1994) have shown that neurons in laminae VI, VII, VIII, and X, which are rhythmically active during fictive locomotion, are activated by MLR stimulation at latencies that are consistent with those observed for negative field potentials in the present study. Lesion studies on the chick embryo have led to the conclusion that the critical neurons involved in alternating activity in flexor and extensor motoncurons are located close to and dorsomedial to the motoneurons (Ho and O'Donovan, 1993). Similar studies in the in vitro neonatal rat preparation show that the medial portion of the ventral horn, including the intermediate zone and lamina $X$, are necessary for rhythmicity (Kjaerulff and Kiehn, 1994).

Some neurons in laminae VI and VII in the midlumbar segments have been shown to be activated by stimulation of the cuneiform nucleus at monosynaptic and disynaptic segmental latencies (Edgley et al., 1988). In decerebrate animals, cells similarly identified are excited at similar latencies by stimuli applied to the MLR and are rhythmically active during MLR-evoked fictive locomotion (Shefchyk et al., 1990). These interneurons have been shown to receive monosynaptic group II muscle afferent input from various hindlimb muscle nerves as well as inputs from group Ia muscle spindle, articular, and cutaneous afferents (Cavallari et al., 1987; Edgley and Jankowska, 1987a,b; Edgley et al., 1988). Other MLR-activated interneurons within laminae VI and VII of the mid- and caudolumbar segments may also contribute to the production of these and other (late) negative field potentials (Jordan and Noga, 1991). In addition, ascending spinal border neurons (possibly ventral spinocerebellar tract neurons; see Hubbard and Oscarsson, 1962; Burke et al., 1971) that have axonal collaterals to spinal gray

$\leftarrow$

Figure 8. Isopotential maps of intraspinal field potentials recorded in the L4-L6 spinal segments during MLR-evoked fictive locomotion. Maps are obtained at various latencies following stimulation of the MLR. The latencies are numbered to correspond to the numbered open arrowheads in Figure 5. The latencies 5.3, 6.5, and $18.3 \mathrm{msec}$ (from lines 2, 3, and 5 of Fig. 5) correspond to the peaks of the P2, P3, and P4 cord dorsum potentials, respectively. The earliest field potentials were evident at $4.3 \mathrm{msec}$ (immediately after the peak of the P1 cord dorsum potential) in lamina VII or near the border of lamina VI and VII (in the L6 scgment). At the peak of the P2 cord dorsum potential, negative field potentials were largest in laminae VII and VIII in all three spinal segments and in the lateral part of laminae VI and VII in the L6 segment. At 6.5 msec, negative field potentials were also observed in lamina IX. Peak amplitudes occurred around $9.1 \mathrm{msec}$ for longer latency field potentials in laminae VI-VIII and for lamina IX negative potentials. During the peak of the P4 cord dorsum potential, negative field potentials were still apparent but at substantially reduced amplitudes. See text for further details. 
L4

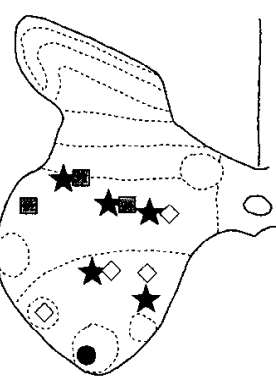

Figure 9. Distribution of all MLRevoked negative field potential foci (current sinks) detected in field potential mapping experiments. Segmental latencies of onset for each field potential foci are plotted according to the indicated symbols.
L5 $\mathrm{L} 6 / 7$

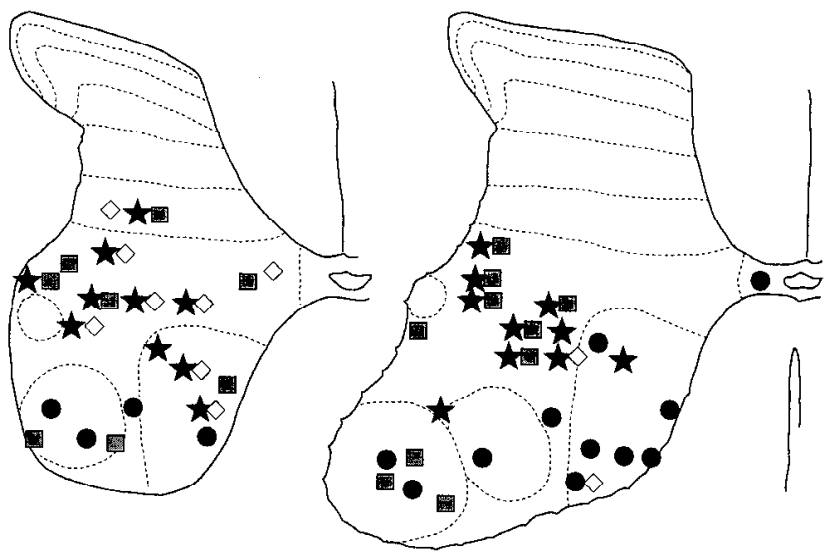

areas within the same segment (Bras et al., 1988) may also contribute to excitation of spinal neurons during fictive locomotion since they are rhythmically active during MLR-evoked fictive locomotion and receive short-latency MLR excitation (Carr et al., 1994)

The focus of electrical activity in lamina VIII of mid- and lower lumbar spinal segments may be due to activity in lamina VIII cells activated by cuneiform nucleus stimulation (Jankowska and Noga, 1990) and which have been shown to be interposed in crossed reflex pathways (Harrison et al., 1986). This would be consistent with the observation that many spinal interneurons in lamina VIII that are activated by MLR stimulation show rhythmic activity that is phase-locked to the locomotor step cycle of the contralateral side during MLR-evoked fictive locomotion (Jordan and Noga, 1991). Low strength stimulation of the cuneiform nucleus was found to activate contralaterally projecting midlumbar lamina VIII interneurons (Jankowska and Noga, 1990) at a latency similar to that observed for the production of carly lamina VIII negative field potentials.

The physiological role of neurons located in lamina $X$ and the medial lamina VII of the L5-6 spinal segments, which are activated by MLR stimulation, is not clear. Spinal interneurons in this region are rhythmically active during MLR-evoked fictive locomotion and may show phase-locked activity related to the flexor or extensor phase of the step cycle on the ipsilateral or contralateral sides (Jordan and Noga, 1991). The recent finding that neurons near the central canal of the in vitro rat spinal cord exhibit $N$-methyl-D-aspartate-mediated bursting properties is consistent with a role for these neurons in the generation of the locomotor rhythm (Hochman et al., 1994). Because many cells in this area project directly to motoneurons, their activation could result in longer latency MLR-evoked negative field potentials in motoneurons. Actions of these cells could also be directed on other spinal interneurons either locally (Honda and Perl, 1985) or distally (Molenaar and Kuypers, 1978; Matsushita et al., 1979; English et al., 1985) or on cells within the brain (e.g., reticular formation, nucleus cuneiformis, thalamus, and cerebellum) (Snyder et al., 1978; Giesler et al., 1981; Kevetter et al., 1982; Nahin et al., 1983).

Latency measurements of cord dorsum P-waves and MLRevoked intraspinal field potentials suggest that they are produced by common synaptic events. Thus, the cord dorsum positive waves may reflect the activation of interneurons and motoneurons in the pathway that leads to locomotion. The P2 wave occurs at a time that should correspond to monosynaptic activation of interneurons from reticulospinal fibers. The P3 wave is coincident with the di- or trisynaptic activation of motoneurons and other interneurons that may be responsible for longer latency postsynaptic potentials in motoneurons (Shefchyk and Jordan, 1985; Noga, 1988). The P4 wave was sometimes accompanied by the appearance of discrete field potentials in lamina VII or the maintained depolarization of spinal neurons in the intermediate zone and ventral horn of the spinal gray. The similarity between the pattern of activity in laminae VI-VIII during P2/3 and P4 suggests that the P4 wave may be produced by activity in the same neurons. Such a "rebound" of interneuronal activity is consistent with our previuus suggestion (Shefchyk and Jordan, 1985) that the MLR stimulus activates a neuronal circuit with oscillatory capability. Rebound excitation of interneurons in this region of the spinal cord has also been observed during intracellular and extracellular recording from neurons activated by MLR stimulation (Jordan and Noga, 1991). Although the coin-

Figure 10. Modulation of MLR-evoked intraspinal field potentials during fictive locomotion. Intraspinal field potentials are sorted according to their occurrence during the normalized step cycle. Isopotential maps in $A$ and $B$ are made at latencies of 5.3 and $9.1 \mathrm{msec}$ and correspond to peaks of "early" and "late" lamina VII field potentials (see lines 2, 4 in Fig. $5 \mathrm{C}$ ). Note the slight differences in the position and amplitude of the current sink foci recorded during flexion or extension. Graphs of field potential amplitude and ENG activity are sorted according to their occurrence in the step cycle as defined by the onset of activity in the ipsilateral TA ENG. Panels below isopotential maps indicate the amplitude of the early and late field potentials indicated in the isopotential maps ( $a$ and $b$, above). Values are expressed in $\mu \mathrm{V}$ with the largest potentials directed downward. The flexion $(f)$ and extension $(e)$ phases of the step cycle are indicated. TA, tibialis anterior; $A B$, anterior biceps; $i$, ipsilateral to side of MLR stimulation; $f p$, field potential. MLR stimulation strengths: $220 \mu \mathrm{A}, 19.5 \mathrm{~Hz}, 1.0 \mathrm{msec}$ duration. 
$\begin{array}{llll}\text { A } & 5.3 \mathrm{msec} & \text { B } & 9.1 \mathrm{msec}\end{array}$
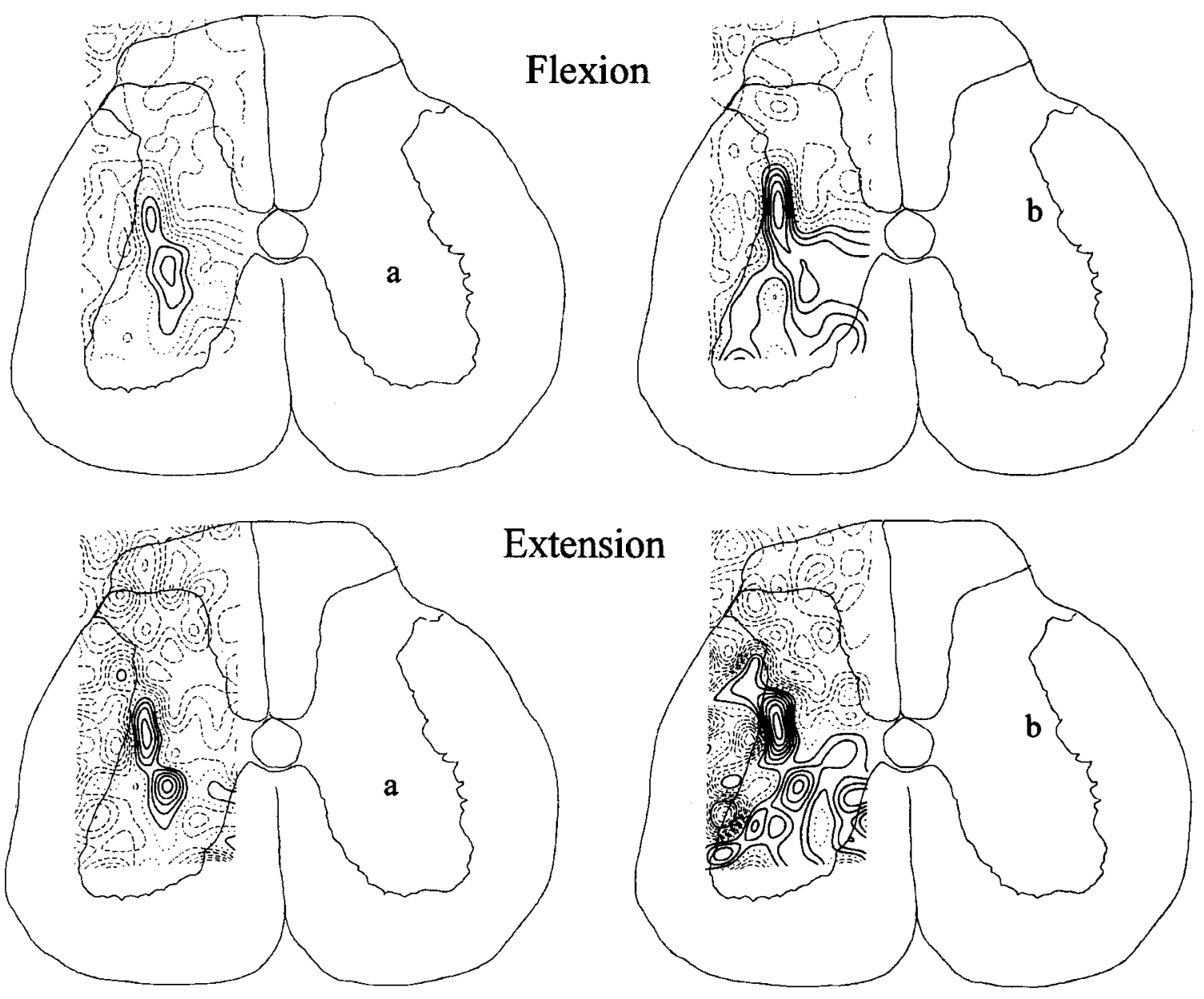

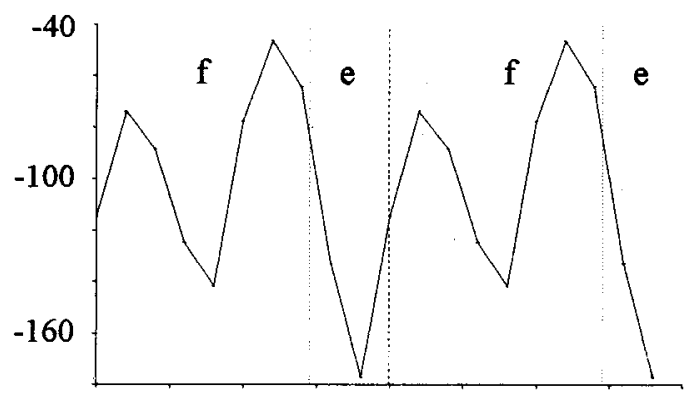

fp (a) amplitude ( $\mu \mathrm{V})$ vs step cycle

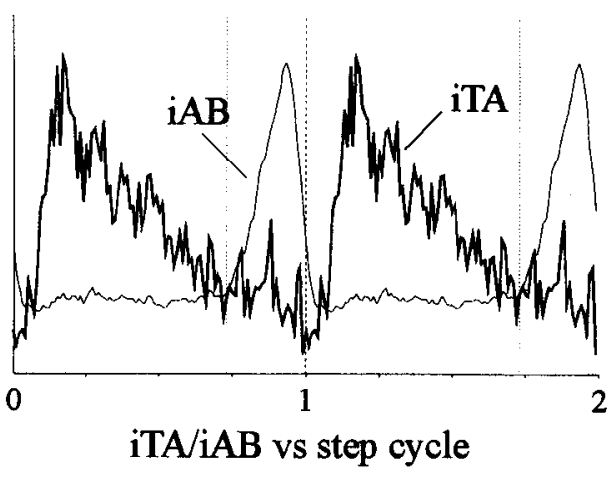

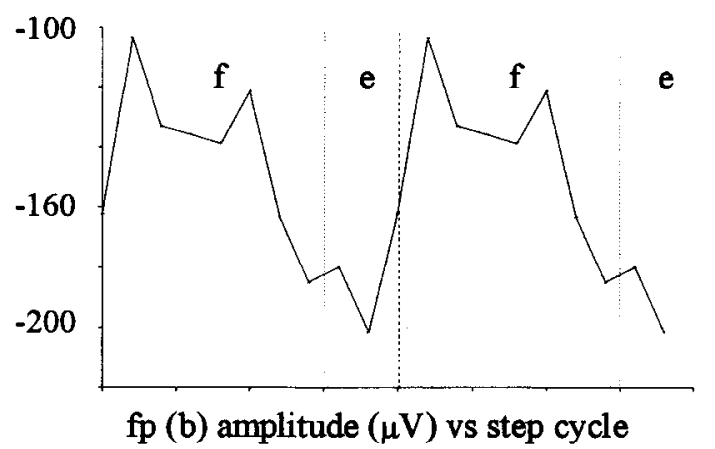

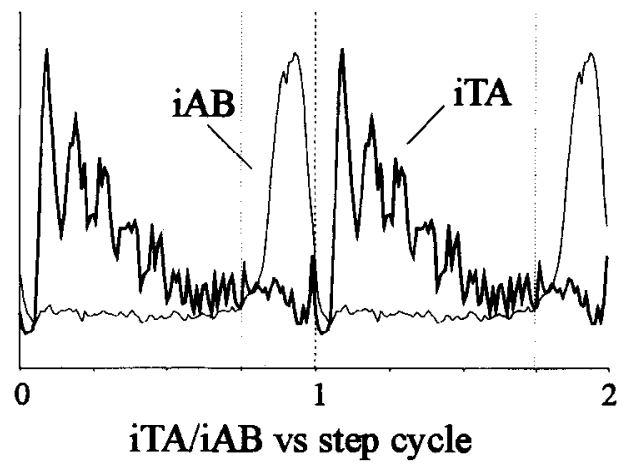


cidence of $\mathrm{P}$-wave and $\mathrm{N}$-wave activity suggests that they are produced by the same processes, the possibility that later components of the cord dorsum potential are due to activity in slow conducting axons cannot be ruled out.

Some components of the cord dorsum positive waves may also reflect processes giving rise to presynaptic depolarization of the terminals of primary afferent fibers, interneurons, and/or descending fibers. This view would be favored over the possibility that stimulation of the MLR evoked inhibitory postsynaptic potentials in dorsal horn interneurons and, therefore, positive extracellular field potentials, since inhibition is not generally observed in dorsal horn neurons during stimulation of the ventral cord pathways (Skinner et al., 1970). Evidence in favor of the idea of a presynaptic control of transmission through interneuronal and descending pathways in the spinal cord has been recently obtained (Alford et al., 1991; Christenson et al., 1991; Jiménez et al., 1991). Depolarization of a variety of primary afferents occurs during fictive locomotion (see review by Sillar, 1991) possibly resulting in a depression of transmission from muscle spindle afferents to first order spinal neurons following stimulation of the cuneiform nucleus (Noga et al., 1991b).

In conclusion, this study provides electrophysiological evidence for the location of the interneurons in the short-latency pathway from the MLR to the motoneurons for the initiation of locomotion (Shefchyk and Jordan, 1985; Noga, 1988). Further studies are needed for the electrophysiological and anatomical identification of these neurons. The locations of the field potentials related to the activity of cells important for the initiation of locomotion are likely to be useful for the detection of sites where locomotion-related neurons can be sampled with microelectrodes. It is expected that detailed knowledge of the functional characteristics of these neurons will be essential to understanding the spinal cord mechanism for the initiation and control of locomotion.

\section{References}

Alford S, Christenson J, Grillner S (1991) Presynaptic GABAa and GABAb receptor-mediated phasic modulation in axons of spinal motor interneurons. Eur $\mathbf{J}$ Neurosci 3:107-117.

Alstermark B, Kummel H (1986) Transneuronal labeling of neurones projecting to forelimb motoneurones in cats performing different Inovements. 376:387-391.

Armstrong DM (1986) Supraspinal contributions to the initiation and control of locomotion in the cat. Prog Neurobiol 26:273-361.

Arshavskii YI, Berkinblit MB, Gelfand IM, Orlovskii GN, Fukson OI (1972) Activity of the neurones of the ventral spinocerebellar tract during locomotion. Biofizika 17:883-890.

Arshavsky YI, Orlovsky GN, Pavlova GA, Popova LB (1986) Activity of $\mathrm{C} 3-\mathrm{C} 4$ propriospinal neurons during fictitious forelimb locomotion in the cat. Brain Res 363:354-357.

Baev KV, Degtyarenko AM, Zavadskaya TV, Kostyuk PG (1979) Activity of lumbar interneurons during fictitious locomotion in thalamic cats. Neurophysiology 11:329-338.

Barajon I, Gossard J-P, Hultborn H (1992) Induction of fos expression by activity in the spinal rhythm generator for scratching. Brain Res 588:168-172.

Bras H, Cavallari P, Jankowska E (1988) Demonstration of initial axon collaterals of cells of origin of the ventral spinocerebellar tract in the cat. I Comp Neurol 273:584-592.

Burke R, Lundberg A, Weight F (1971) Spinal border cell origin of the ventral spinocerebellar tract. Exp Brain Res 12:283-294.

Carr PA, Noga BR, Jordan LM (1994) Intracellular labeling of cat spinal neurons using a tetramethylrhodamine-dextran amine conjugate. Brain Res Bull 34:447-451.

Cavallari P, Edgley SA, Jankowska E (1987) Post-synaptic actions of midlumbar interneurons on motoneurones of hind-limb muscles in the cat. J Physiol (Lond) 385:393-413.

Christenson J, Bongianni F, Grillner S, Hökfelt T (1991) Putative GABAergic input to axons of spinal interneurons and primary sensory neurons in the lamprey spinal cord as shown by intracellular Lucifer Yellow and GABA immunohistochemistry. Brain Res 538:313-318.

Dai X, Douglas JR, Nagy JI, Noga BR, Jordan LM (1990) Localization of spinal neurons activated during treadmill locomotion using the c-fos immunohistochemical method. Soc Neurosci Abstr 16:889.

Deliagina TG, Orlovsky GN, Pavlova GA (1983) The capacity for generation of rhythmic oscillations is distributed in the lumbosacral spinal cord of the cat. Exp Brain Res 53:81-90.

Edgerton VR, Grillner S, Sjöström A, Zangger P (1976) Central generation of locomotion in vertebrates. In: Advances in behavioural biology, Vol 18, Neural control of locomotion (Herman RM, Grillner S, Stein PSG, Stuart DG, eds), pp 439-464. New York: Plenum.

Edgley SA, Jankowska E (1987a) Field potentials generated by group II muscle afferents in the middle lumbar segments of the spinal cord. J Physiol (Lond) 385:393-413.

Edgley SA, Jankowska E (1987b) An interneuronal relay for group I and group II muscle afferents in middle lumbar segments of the cat spinal cord. J Physiol (Lond) 389:647-674.

Edgley SA, Jankowska E, Shefchyk SJ (1988) Evidence that mid-lumbar neurones in reflex pathways from group II afferents are involved in locomotion in the cat. J Physiol (Lond) 403:57-71.

English AW, Tigges J, Lennard PR (1985) Anatomical organization of long ascending propriospinal neurons in the cat spinal cord. J Comp Neurol 240:349-358.

Feldman AG, Orlovsky GN (1975) Activity of interneurons mediating reciprocal la inhibition during locomotion. Brain Res 84:181-194.

Fortier P, Kriellaars D, Jordan L (1988) Mapping of lumbar cord potentials evoked by stimulation of the mesencephalic locomotor region (MLR) in the cat. Soc Neurosci Abstr 14:264.

Fu TC, Santini M, Schomburg ED (1974) Characteristics and distribution of spinal focal synaptic potentials generated by group II muscle afferents. Acta Physiol Scand 91:298-313.

Garcia-Rill E (1986) The basal ganglia and the locomotor regions. Brain Res Rcv 11:47-63.

Garcia-Rill E, Skinner RD, Gilmore SA (1981) Palladial projections to the mesencephalic locomotor region (MLR) in the cat. Am J Anat 161:311-321.

Garcia-Rill E, Skinner RD, Gilmore SA, Owings R (1983) Connections of the mesencephalic locomotor region (MLR). II. Afferents and efferents. Brain Res Bull 10:63-71.

Garcia-Rill E, Skinner RD, Fitzgerald JA (1985) Chemical activation of the mesencephalic locomotor region. Brain Res 330:43-54.

Giesler GJ Jr, Spiel HR, Willis WD (1981) Organization of spinothalamic tract axons within the rat spinal cord. J Comp Neurol 195: $243-252$.

Grillner S, Zangger P (1979) On the central generation of locomotion in the low spinal cat. Exp Brain Res 34:241-261.

Hanison PJ, Jankowska E, Zytnicki D (1986) Lamina VIII interneurons interposed in crossed reflex pathways in the cat. J Physiol (Lond) 371:147-166.

Hishinuma M, Yamaguchi T (1990) Cervical interneurons oligosynaptically excited from primary afferents and rhythmically active during forelimb fictive locomotion in the cat. Neurosci Lett 111:287291.

Ho S, O'Donovan MJ (1993) Regionalization and intersegmental coordination of rhythm-generating networks in the spinal cord of the chick embryo. J Neurosci 13:1354-1371.

Hochman S, Jordan LM, MacDonald JF (1994) N-Methyl-D-aspartate receptor-mediated voltage oscillations in neurons surrounding the central canal in slices of rat spinal cord. J Neurophysiol 72: 565577.

Honda CN, Perl ER (1985) Functional and morphological features of neurons in the midline region of the caudal spinal cord of the cat. Brain Res 340:285-295.

Hoover JE, Durkovic RG (1992) Retrograde labeling of lumbosacral interneurons following injections of red and green fluorescent microspheres into hindlimb motor nuclei of the cat. Somatosens Motor Res 9:211-226.

Hubbard JI, Oscarsson O (1962) Localization of the cell bodies of the ventral spinocerebellar tract in lumbar segments of the cat. J Comp Neurol 118:199-204. 
Ichikawa, Y, Terakado Y, Yamaguchi T (1991) Last-order interneurons controlling activity of elbow extensor motoneurones during forelimb fictive locomotion in the cat. Neurosci Lett 121:37-39.

Jankowska E (1986) Further indications for enhancement of retrograde transneuronal transport of WGA-HRP by synaptic activity. Brain Res 341:403-408.

Jankowska E, Noga BR (1990) Contralaterally projecting lamina VIII interneurons in middle lumbar segments in the cat. Brain Res 535: $327-330$.

Jankowska E, Skoog B (1986) Labelling of midlumbar neurons projecting to cat hindlimb motoneurons by transneuronal transport of a horseradish peroxidase conjugate. Neurosci Lett 71:163-168.

Jasmin L, Gugas KR, Ahlgren SC, Levine JD, Basbaum AI (1994) Walking evokes a distinctive pattern of fos-like immunoreactivity in the caudal brainstem and spinal cord of the rat. Neuroscience 58: $275-286$.

Jiménez I, Rudomin P, Enriquez M (1991) Differential effects of (-)baclofen on Ia and descending monosynaptic EPSPs. Exp Brain Res $85: 103-113$

Jordan LM (1986) Initiation of locomotion from the mammalian brainstem. In: Wenner-Gren Centre international symposium series, Vol 45, Neurobiology of vertebrate locomotion (Grillner S, Stein PSG, Stuart DG, Forssberg H, Herman RM, eds), pp 21-37. London: Macmillan.

Jordan LM (1991) Brainstem and spinal cord mechanisms for the initiation of locomotion. In: Neurobiological basis of human locomotion (Shimamura M, Grillner S, Edgerton VR, eds), pp 3-20. Tokyo: Japan Scientific Societies.

Jordan LM, Noga BR (1991) Spinal interneurons synaptically activated by stimuli applied to the mesencephalic locomotor region. Soc Neurosei Abstr 17:1223.

Kazennikov OV, Shik ML, Yakovleva GV (1983) Responses of upper cervical spinal neurons in cats to stimulation of the brain-stem locomotor region at different frequencies. Neurophysiology 15:256261

Kevetter GA, Haber LH, Yezierski RP, Chung JM, Martin RF, Willis WD (1982) Cells of origin of the spinoreticular tract in the monkey. J Comp Neurol 207:61-74.

Kjaerulff O, Kiehn O (1994) Localization of the central pattern generator for hindlimb locomotion in the neonatal rat in vitro. A lesion study. Soc Neurosci Abstr 20.

Kjaerulff O, Barajon I, Kiehn O (1994) Sulforhodamine-labelled cells in the nconatal rat spinal cord following chemically induced loco motor activity in vitro. J Physiol (Lond) 478:265-273.

Matsushita M, Ikeda M, Hosoya Y (1979) The location of spinal neurons with long descending axons (long descending propriospinal tract neurons) in the cat: a study with the horseradish peroxidase technique. J Comp Neurol 184:63-80.

McCrea DA, Pratt CA, Jordan LM (1980) Renshaw cell activity and recurrent effects on motoneurons during fictive locomotion. J Neurophysiol 44:475-488.

Molenaar I, Kuypers HGJM (1978) Cells of origin of propriospinal fibers and of fibers ascending to supraspinal levels. A HRP study in cat and rhesus monkey. Brain Res 152:429-450.

Mortin LI, Stein PSG (1989) Spinal cord segments containing key elements of the central pattern generators for three forms of scratch reflex in the turtle. J Neurosci 9:2285-2296.

Nahin RL, Madsen AM, Giesler GJ Jr (1983) Anatomical and physiological studies of the gray matter surrounding the spinal cord central canal. J Comp Neurol 220:321-335.

Noga BR (1988) An investigation of descending brainstem pathways involved in the production of locomotion. $\mathrm{PhD}$ thesis, University of Manitoba.

Noga BR, Shefchyk SJ, Jamal J, Jordan LM (1987a) The role of Renshaw cclls in locomotion: antagonism of their excitation from motor axon collaterals with intravenous mecamylamine. Exp Brain Res 66 $99-105$.

Noga BR, Shefchyk SJ, Jordan LM (1987b) Localization of last-order interneurons participating in the production of locomotion in the cat. Soc Neurosci Abstr 13:826.

Noga BR, Kettler J, Jordan LM (1988) Locomotion produced in mesencephalic cats by injections of putative transmitter substances and antagonists into the medial reticular formation and the pontomedullary locomotor strip. J Neurosci 8:2074-2086.

Noga BR, Kriellaars DJ, Jordan LM (1991a) The effect of selective brainstem or spinal cord lesions on treadmill locomotion evoked by stimulation of the mesencephalic or pontomedullary locomotor regions. J Neurosci 11:1691-1700.

Noga BR, Jankowska E, Skoog B (1991b) Depression of transmission from group II muscle afferents by electrical stimulation of the cuneiform nucleus and subcuneiform region in the cat. Soc Neurosci Abstr 17:1024.

Orlovsky GN (1969) Electrical activity in the brainstem and descending pathways in guided locomotion. Fiziol Zh (SSSR) 55:437-444.

Orlovskii GN, Feldman AG (1972) Classification of lumbosacral neurons by their discharge pattern during evoked locomotion. Neurophysiology 4:311-317.

Pratt C $\Lambda$, Jordan LM (1987) Ia inhibitory interneurons and Renshaw cells as contributors to the spinal mechanisms of fictive locomotion. J Neurophysiol 57:56-71.

Rotto-Percelay DM, Wheeler JG, Osorio FA, Platt KB, Loewy AD (1992) Transneuronal labeling of spinal interneurons and sympathetic preganglionic neurons after pseudorabies virus injections in the rat medial gastrocnemius muscle. Brain Res 574:291-306.

Shefchyk SJ, Jordan LM (1985) Excitatory and inhibitory postsynaptic potentials in alpha-motoneurons produced during fictive locomotion by stimulation of the mesencephalic locomotor region. J Neurophysiol 53:1345-1355.

Shefchyk S, McCrea D, Kriellaars D, Fortier P, Jordan L (1990) Activity of interneurons within the L4 segment of the cat during brainstem-evoked fictive locomotion. Exp Brain Res 80:290-295.

Shik ML, Severin FV, Orlovsky GN (1966) Control of walking and running by means of electrical stimulation of the mid-brain. Biophysics 11:756-765.

Shik ML, Severin FV, Orlovsky GN (1967) Structures of the brainstem responsible for evoked locomotion. Fiziol Zh 53:1125-1132.

Shik ML, Orlovsky GN, Severin FV (1968) Locomotion in the mesencephalic cat elicited by stimulation of the pyramids. Biophysics 13: 143-152.

Sillar KT (1991) Spinal pattern generation and sensory gating mechanisms. Curr Opinion Ncurobiol 1:583-589.

Skinner RD, Remmel RS (1978) Monosynaptic inputs to lumbar interneurons from the lateral vestibulospinal tract and the medial longitudinal fasciculus. Neurosci Let 10:259-264.

Skinner RD, Willis WD (1970) Spinal cord potentials produced by ventral cord volleys in the cat. Exp Neurol 27:305-317.

Skinner RD, Willis WD, Hancock MB (1970) Actions of ventral cord pathways on spinal neurons. Exp Neurol 27:318-333.

Snyder RL, Faull RLM, Mehler WR (1978) A comparative study of the neurons of origin of the spinocerebellar afferents in the rat, cat and squirrel monkey based on the retrograde transport of horseradish peroxidase. J Comp Neurol 181:833-852.

Spläth H (1974) Spline algorithms for curves and surfaces. Winnipeg: Utilitas Mathematica.

Steeves JD, Jordan LM (1980) Localization of a descending pathway in the spinal cord which is necessary for controlled treadmill locomotion. Neurosci Lett 20:283-288.

Steeves JD, Jordan LM (1984) Autoradiographic demonstration of the projections from the mesencephalic locomotor region. Brain Res 307: 263-276.

Terakado Y, Yamaguchi T (1990) Last-order interneurons controlling activity of elbow flexor motoneurones during forelimb fictive locomotion in the cat. Neurosci Lett 111:292-296.

Viala D, Buisseret-Delmas C, Portal JJ (1988) An attempt to localize the lumbar locomotor generator in the rabbit using 2-deoxy- $\left[{ }^{14} \mathrm{C}\right] \mathrm{glu}-$ cose autoradiography. Neurosci Lett 86:139-143.

Viala D, Viala G, Jordan M (1991) Interneurons of the lumbar cord related to spontaneous locomotor activity in the rabbit. Exp Brain Res 84:177-186.

Willis WD (1980) Spinal cord potentials. In: The spinal cord and its reaction to traumatic injury (Windle WF, ed), pp 159-187. New York: Dekker.

Yamaguchi T (1991) Cat forelimb stepping generator. In: Neurobiological basis of human locomotion (Shimamura M, Grillner S, Edgerton VR, eds), pp 103-115. Tokyo: Japan Scientific Societies.

Yamaguchi T (1992) Activity of cervical neurons during forelimb fictive locomotion in decerebrate cats. Jpn J Physiol 42:501-514. 